\title{
p66Shc deficiency enhances CXCR4 and CCR7 recycling in CLL B cells by facilitating their dephosphorylation-dependent release from $\beta$ - arrestin at early endosomes
}

\author{
Laura Patrussi ${ }^{1}$ - Nagaja Capitani ${ }^{1,2}$ - Francesca Cattaneo ${ }^{1}$. Noemi Manganaro' ${ }^{1}$ Alessandra Gamberucci ${ }^{3}$. \\ Federica Frezzato $\mathbb{1}^{4,5} \cdot$ Veronica Martini ${ }^{4,5}$. Andrea Visentin ${ }^{4,5} \cdot$ Pier Giuseppe Pelicci ${ }^{6} \cdot$ Mario M. D'Elios ${ }^{2}$. \\ Livio Trentin ${ }^{4,5} \cdot$ Gianpietro Semenzato $^{4,5} \cdot$ Cosima T. Baldari $^{1}$
}

Received: 28 April 2017 / Revised: 6 October 2017 / Accepted: 13 November 2017

(c) Macmillan Publishers Limited, part of Springer Nature 2018

\begin{abstract}
Neoplastic cell traffic abnormalities are central to the pathogenesis of chronic lymphocytic leukemia (CLL). Enhanced CXC chemokine receptor-4 (CXCR4) and chemokine receptor-7 (CCR7) recycling contributes to the elevated surface levels of these receptors on CLL cells. Here we have addressed the role of p66Shc, a member of the Shc family of protein adaptors the expression of which is defective in CLL cells, in CXCR4/CCR7 recycling. p66Shc reconstitution in CLL cells reduced CXCR4/CCR7 recycling, lowering their surface levels and attenuating B-cell chemotaxis, due to their accumulation in Rab5

${ }^{+}$endosomes as serine-phosphoproteins bound to $\beta$-arrestin. This results from the ability of p66Shc to inhibit $\mathrm{Ca}^{2+}$ and PP2B-dependent CXCR4/CCR7 dephosphorylation and $\beta$-arrestin release. We also show that ibrutinib, a Btk inhibitor that promotes leukemic cell mobilization from lymphoid organs, reverses the CXCR4/CCR7 recycling abnormalities in CLL cells by increasing p66Shc expression. These results, identifying p66Shc as a regulator of CXCR4/CCR7 recycling in B cells, underscore the relevance of its deficiency to CLL pathogenesis and provide new clues to the mechanisms underlying the therapeutic effects of ibrutinib.
\end{abstract}

Laura Patrussi and Nagaja Capitani contributed equally to this work.

Electronic supplementary material The online version of this article (https://doi.org/10.1038/s41388-017-0066-2) contains supplementary material, which is available to authorized users.

Laura Patrussi patrussi2@unisi.it

$\triangle$ Cosima T. Baldari baldari@unisi.it

1 Department of Life Sciences, University of Siena, Siena, Italy

2 Department of Clinical and Experimental Medicine, University of Florence, Florence, Italy

3 Department of Molecular and Developmental Medicine, University of Siena, Siena, Italy

4 Venetian Institute of Molecular Medicine, Padua, Italy

5 Department of Medicine, Hematology and Clinical Immunology Branch, Padua University School of Medicine, Padua, Italy

6 European Institute of Oncology, Milan, Italy

\section{Introduction}

The stromal microenvironment has emerged as a major player in the survival and expansion of neoplastic cells in chronic lymphocytic leukemia (CLL), a hematological neoplasm characterized by the progressive accumulation of mature $\mathrm{CD}^{+} \mathrm{B}$ cells in blood, bone marrow $(\mathrm{BM})$ and secondary lymphoid organs (SLOs) [1-3]. B lymphocyte homing to SLOs and BM is regulated by the chemokine receptors chemokine receptor-7 (CCR7) and CXC chemokine receptor-4 (CXCR4), respectively, which respond to stroma-derived ligands [4-8]. This activity is counteracted by sphingosine-1-phosphate (S1P) receptors that promote lymphocyte egress from their homing sites toward the S1Prich circulatory fluids [9]. CLL cells display abnormally high levels of surface CXCR4 and CCR7 [10-12] concomitant with a defect in sphingosine-1-phosphate receptor 1 (S1PR1) expression [13], resulting in an altered balance between entry and egress signals that might prolong leukemic cell residency in the pro-survival stromal niche.

The magnitude and duration of the cellular response to chemokines are regulated by receptor desensitization/ 
a

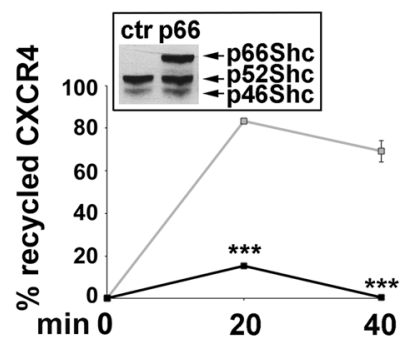

C

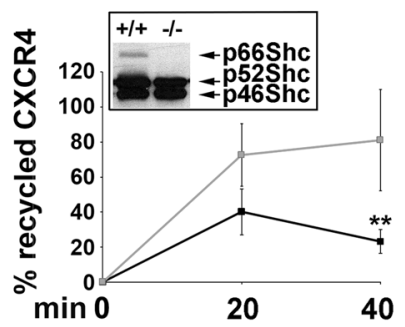

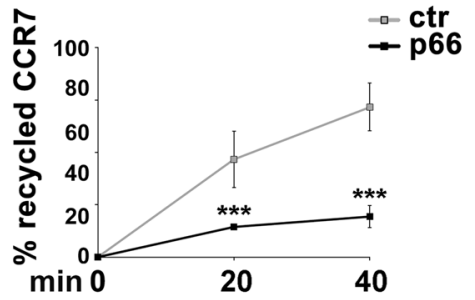

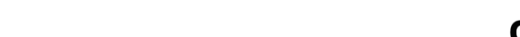

b

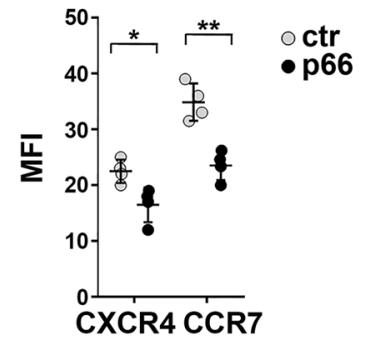

d

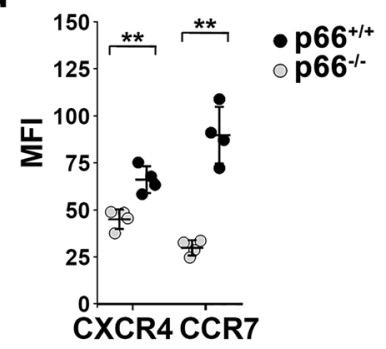

e

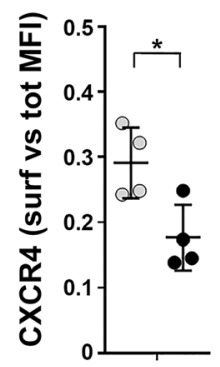

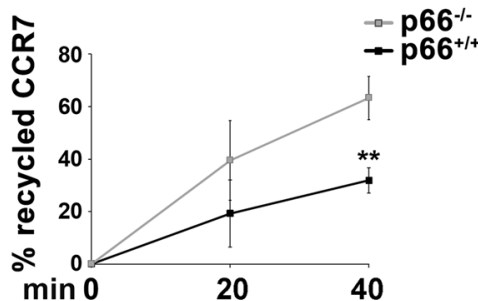

f
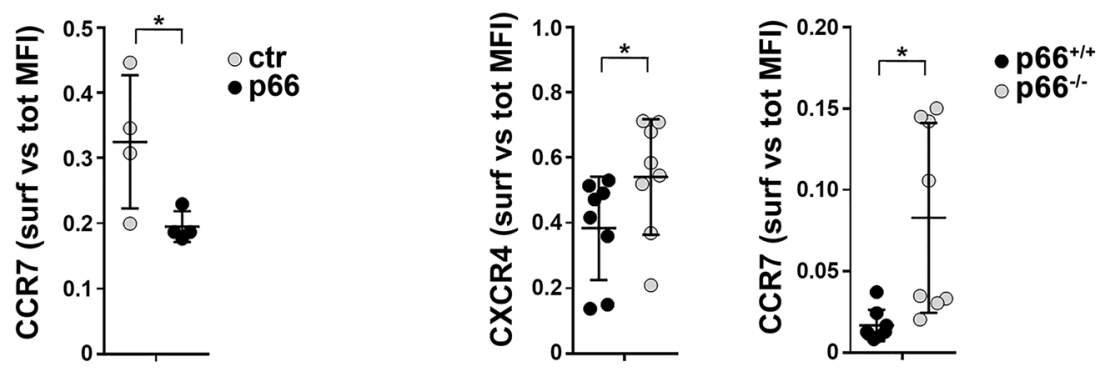

g

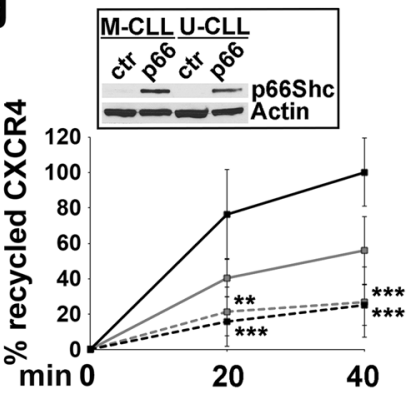

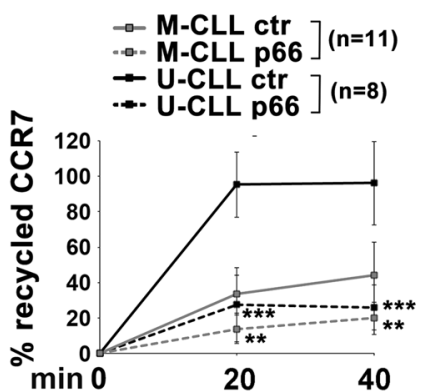

h

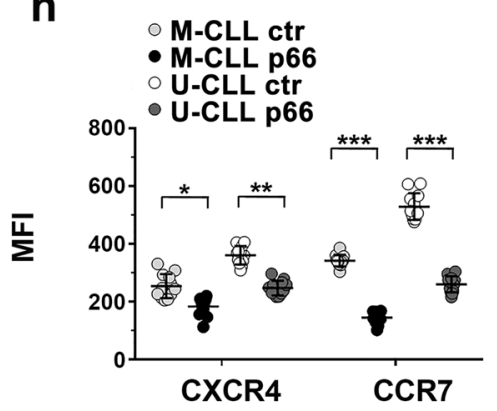

i

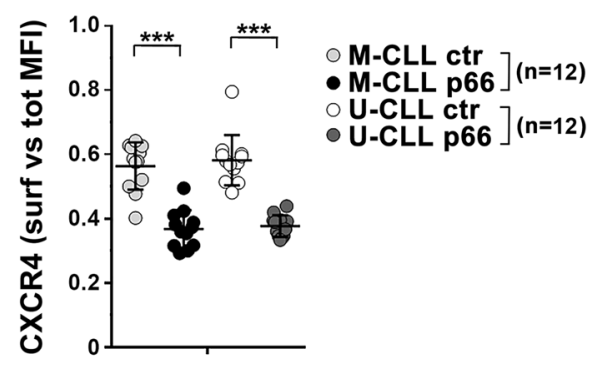

resensitization, similar to other G-protein-coupled receptors (GPCR). Following serine/threonine phosphorylation and $\beta$ arrestin binding, GPCRs are internalized and targeted to
$\mathrm{Rab5}^{+}$(Ras-related in brain 5) endosomes, wherefrom on dephosphorylation they recycle to the plasma membrane or are alternatively routed to lysosomes for degradation [14- 
Fig. 1 p66Shc negatively regulates CXCR4 and CCR7 recycling in B cells. a, c Flow cytometric analysis of CXCR4/CCR7 recycling in MEC B cells stably transfected with empty vector (ctr) or with a vector encoding p66Shc (p66) a, or in splenic B cells purified from wild-type $\left(\mathrm{p} 66^{+/+}\right)$or p66Shc ${ }^{-/-}\left({\left.\mathrm{p} 66^{-/}\right)}^{-}\right.$mice c. Data are presented as $\%$ of internalized receptors that have recycled to the cell surface at the indicated times and refer to duplicate samples from four independent experiments a or to duplicate samples from eight $\mathrm{p} 66 \mathrm{Shc}^{+/+}$and eight p66Shc ${ }^{-/-}$mice c. The immunoblot analysis with anti-Shc antibodies of postnuclear supernatants from ctr and p66 MEC B cells a or from purified splenic B cells from $\mathrm{p} 66 \mathrm{Shc}^{+/+}$and $\mathrm{p} 66 \mathrm{Shc}^{-/}$mice $\mathbf{c}$ are shown on the top of the respective panels. b, d Flow cytometric analysis of CXCR4/CCR7 surface staining in ctr and p66 MEC B cells $(\mathbf{b}, n=4)$ or in splenic B cells from eight p66Shc ${ }^{+/+}$and eight p66Shc ${ }^{-1-}$ mice d. e, f Ratio of surface-to-total MFI of CXCR4 and CCR7 in ctr and p66 MEC B cells $(\mathbf{e}, n=4)$, or in splenic B cells purified from p66Shc ${ }^{+/+}$or p66Shc ${ }^{-/-}$mice (f, duplicate samples from eight wild-type and eight p66Shc ${ }^{-/}$mice). Data are expressed as ratio $(m e a n \pm S D)$ of MFI in non-permeabilized cells (surface) to permeabilized (total) cells. g Flow cytometric analysis of CXCR4/CCR7 recycling in purified M-CLL $(n=11)$ or U-CLL $(n=8)$ B cells nucleofected with either empty vector (ctr) or an expression construct encoding p66Shc (p66). Data are presented as \% of internalized receptors that have recycled to the cell surface at the indicated times and refer to duplicate samples for each patient. The immunoblot analysis with anti-Shc and anti-actin antibodies of postnuclear supernatants from the CLL transfectants is shown above. $\mathbf{h}$ Flow cytometric analysis of CXCR4/CCR7 surface staining in purified M-CLL $(n=12)$ or U-CLL $(n=12)$ B cells nucleofected as above. i Ratio of surface-tototal MFI of CXCR4 (left) and CCR7 (right) from M-CLL or U-CLL ctr or p66Shc B-cell transfectants. Data are expressed as ratio (mean $\pm \mathrm{SD}$ ) of MFI in non-permeabilized cells (surface) to permeabilized (total) cells. Error bars, SD. Student's $t$-test (unpaired). ${ }^{* * *} p<0.001$; $* * p<0.01 ; * p<0.05$

18]. The mechanism underlying this key dephosphorylation step on CXCR4 and CCR7 is currently unknown. CXCR4 and CCR7 recycling is potentiated in CLL cells, which contributes to their increased surface levels [11], underscoring the importance of characterizing this pathway.

We have implicated a defect of p66Shc, a proapoptotic Shc family member, in CLL pathogenesis [19]. The impairment in p66Shc expression contributes to the apoptosis defects of CLL cells due to its ability to modulate Bcl2 family gene expression [19]. This extends to the genes encoding CCR7 and S1PR1, implicating p66Shc deficiency both in the upregulation of CCR7 expression and in the downmodulation of S1PR1 in CLL cells [13]. Furthermore, p66Shc suppresses CXCR4 and CXCR5 signaling in B cells [20]. Hence the p66Shc expression defect may impact at multiple levels on CLL cell trafficking to promote their accumulation in the stromal niche.

Here we asked whether p66Shc is implicated in homing receptor recycling. We show that p66Shc is a negative regulator of $\mathrm{CXCR} 4 / \mathrm{CCR} 7$ recycling in $\mathrm{B}$ cells and that their enhanced recycling in CLL cells is corrected by restoring p66Shc expression. We show that p66Shc limits CXCR4/CCR7 recycling by inhibiting their
$\mathrm{Ca}^{2+}$ and phosphatase type 2B (PP2B)-dependent dephosphorylation, on which their release from $\beta$-arrestin and transit to recycling endosomes was found to crucially depend. Furthermore, we provide evidence that ibrutinib, a Bruton tyrosine kinase (Btk) inhibitor used in combination therapies for CLL, normalizes the surface levels and subcellular distribution of CXCR4/CCR7 by limiting their recycling via an increase in p66Shc expression.

\section{Results}

\section{p66Shc negatively regulates CXCR4 and CCR7 recycling in B cells}

Based on its ability to attenuate CXCR4 and CXCR5 signaling [20], we investigated the role of p66Shc in recycling of $\mathrm{CXCR} 4$ and the related homing receptor CCR7, using as model the CLL-derived MEC B-cell line, which does not express p66Shc [13], stably transfected with p66Shc-encoding (p66) or empty (ctr) vector. Liganddependent recycling of internalized CXCR4/CCR7 in cells treated with either the respective antibodies (Fig. 1a; Supplementary Figure 1a) or chemokine ligands (Supplementary Figure 1b) was profoundly impaired in the presence of p66Shc, resulting in lower surface CXCR4/CCR7 (Fig. 1b). Ligand-independent CXCR4/CCR7 recycling was also impaired in p66Shc-expressing cells (Supplementary Figure 1c). Similar results were obtained when recycling and surface CXCR4/CCR7 were analyzed in splenic B cells from $\mathrm{p} 66 \mathrm{Shc}^{-/}$mice or wild-type mice, where p66Shc is expressed at physiological levels (Figs. 1c, d). A time course analysis of antibody-induced CXCR4/CCR7 downmodulation showed that p66Shc affected neither the kinetics or the extent of receptor downmodulation (Supplementary Figure 1d). Hence, p66Shc acts as a negative regulator of CXCR4 and CCR7 recycling downstream of their liganddependent internalization.

A substantial proportion of CXCR4/CCR7 is stored in recycling endosomes in $\mathrm{B}$ cells [11]. We asked whether p66Shc may alter the quantitative balance between surface and vesicular CXCR4/CCR7 by interfering with their recycling. CXCR4/CCR7 were quantitated by flow cytometry in the intact and permeabilized MEC B-cell transfectants, as well as on splenic B cells from wild-type and p66Shc ${ }^{-/-}$mice. Surface CXCR4/CCR7 was lower in the presence of p66Shc with a concomitant increase in the intracellular pool (Supplementary Figure 2a and b), resulting in a lower ratio of surface-to-total receptor in p66Shcexpressing cells (Figs. 1e, f). Hence, p66Shc affects the subcellular distribution of both receptors, favoring their association with the endosomal pool. 


\section{p66Shc reconstitution in CLL cells normalizes the chemokine-dependent enhancement in CXCR4/CCR7 recycling and chemotaxis}

CXCR4/CCR7 recycling, as well as ligand-dependent chemotaxis are strongly enhanced in CLL cells, especially in patients with unmutated immunoglobulin Heavy chain variable locus $(I G H V)$ [11]. To assess whether the p66Shc defect in CLL cells [19] accounts for these recycling abnormalities, we measured CXCR4/CCR7 recycling in leukemic cells reconstituted with p66Shc (Fig. 1g). Patients were grouped according to $I G H V$ mutational status (mutated, M-CLL; unmutated, U-CLL). Forced p66Shc expression resulted in a striking decrease in CXCR4/CCR7 recycling in both patient subgroups (Fig. 1g), which led to a reduction in surface CXCR4/CCR7 (Fig. 1h), implicating the p66Shc expression defect in the enhanced ability of CLL cells to recycle these receptors. p66Shc reconstitution in CLL cells also led to a modification in the subcellular distribution of CXCR4/CCR7, with a greater proportion of receptors localized intracellularly to the expense of the plasma membrane (Supplementary Figure 2c), resulting in a lower ratio of surface-to-total receptor (Fig. 1i). Consistent with our previous reports [11, 19], p66Shc reconstitution in CLL cells resulted in a decrease in the mRNA and overall protein levels of CCR7 but did not affect the levels of CXCR4 (Supplementary Figure 3a and b). Hence, although the decreased amount of surface CCR7 in p66Shcexpressing $\mathrm{B}$ cells is partly related to decreased expression, this does not apply to CXCR4, whose decrease is mainly accounted for by reduced recycling.

Concomitant with the recycling-related reduction in surface CXCR4/CCR7 (Supplementary Figure 2C), p66Shc reconstitution in B cells from M-CLL and U-CLL patients resulted in a strong inhibition of CXCL12-/CCL21-dependent adhesion to ICAM-1 (Supplementary Figure 4a) and Fibronectin (Supplementary Figure 4b). p66Shc reversed moreover the abnormally elevated CLL cell migration toward CXCL12/CCL21 (Supplementary Figure 4c and d). Hence, the p66Shc expression defect in CLL cells impinges on their responses to these chemokines at least in part by modulating the levels of the respective surface receptors through recycling.

\section{p66Shc promotes the accumulation of internalized and $\beta$-arrestin-bound CXCR4/CCR7 in Rab5 ${ }^{+}$ endosomes}

To track internalized CXCR4/CCR7, the MEC transfectants were stimulated with CXCL12/CCL21 to induce receptor internalization, then co-stained with antibodies to the respective receptors and for markers of early (Rab5) or recycling (Rab11) endosomes [11, 17]. As expected [11, 17,
18], both receptors colocalized to a significant extent with Rab11 (Supplementary Figure 5) and partially with Rab5 (Fig. 2a) in the control transfectant. Forced p66Shc expression strongly enhanced the colocalization of recycling CXCR4/CCR7 with Rab5 (Fig. 2a), whereas reducing their colocalization with Rab11 (Supplementary Figure 5). Interestingly, CXCL12/CCL21 readily triggered an association of Rab5 with CXCR4/CCR7 in the control transfectant, which was lost at a later time of stimulation, as assessed by immunoprecipitation (Fig. 3a). Conversely, the chemokine-dependent interaction of both receptors with Rab5 was sustained in the presence of p66Shc (Fig. 3a). Hence, internalized CXCR4/CCR7 rapidly transit through $\mathrm{Rab5}^{+}$endosomes to undergo recycling in MEC cells but accumulate in $\mathrm{Rab}^{+}$endosomes in the presence of p66Shc, accounting for their impaired recycling.

GPCR internalization requires $\beta$-arrestin recruitment to serine-phosphorylated residues $[14,15]$, which must be dephosphorylated for $\beta$-arrestin release and receptor recycling [21]. Imaging CXCR4/CCR7 in ctr MEC cells showed a strong but transient colocalization of both receptors with $\beta$-arrestin (Fig. 2b) consistent with their recycling to the plasma membrane (Fig. 1a), as opposed to the sustained colocalization at later times in p66Shc-expressing MEC cells (Fig. 2b). Moreover, the chemokine-triggered interaction of CXCR4/CCR7 with $\beta$-arrestin, as well as Rab5 was found to be long-lasting in p66 cells when compared with ctr cells (Fig. 3a) indicating that, in the presence of p66Shc, CXCR4/CCR7 internalized in response to ligand binding accumulate in association with $\beta$-arrestin in $\mathrm{Rab} 5^{+}$ vesicles and are therefore unable to transit to Rab $11^{+}$ endosomes for recycling.

Both Rab5 and $\beta$-arrestin co-precipitated with p66Shc following stimulation with CXCL12/CCL21, forming a long-lasting complex (Fig. 3b). Together with the ability of CXCR4/CCR7 to interact with p66Shc in a ligandindependent manner (Fig. 3b), this suggests that p66Shc may stabilize their association with $\beta$-arrestin at early endosomes, preventing their traffic along their recycling route.

To understand whether the p66Shc defect in CLL cells, which correlates with enhanced CXCR4/CCR7 recycling, leads to alterations in the dynamics of their interaction with Rab5 or $\beta$-arrestin similar to the MEC transfectants, we compared the colocalization of CXCR4/CCR7 with Rab5 and $\beta$-arrestin in $\mathrm{B}$ cells purified from healthy donors (HDs) and M-CLL or U-CLL patients at a late time point of stimulation with the respective chemokines. A significant CXCR4/CCR7 colocalization with both Rab5 and $\beta$-arrestin was observed in B cells from healthy donors (Figs. 4a, b). This was markedly lower in CLL cells, especially of the UCLL subgroup (Figs. 4a, b). p66Shc reconstitution in CLL cells largely restored CXCR4/CCR7 colocalization with 
a
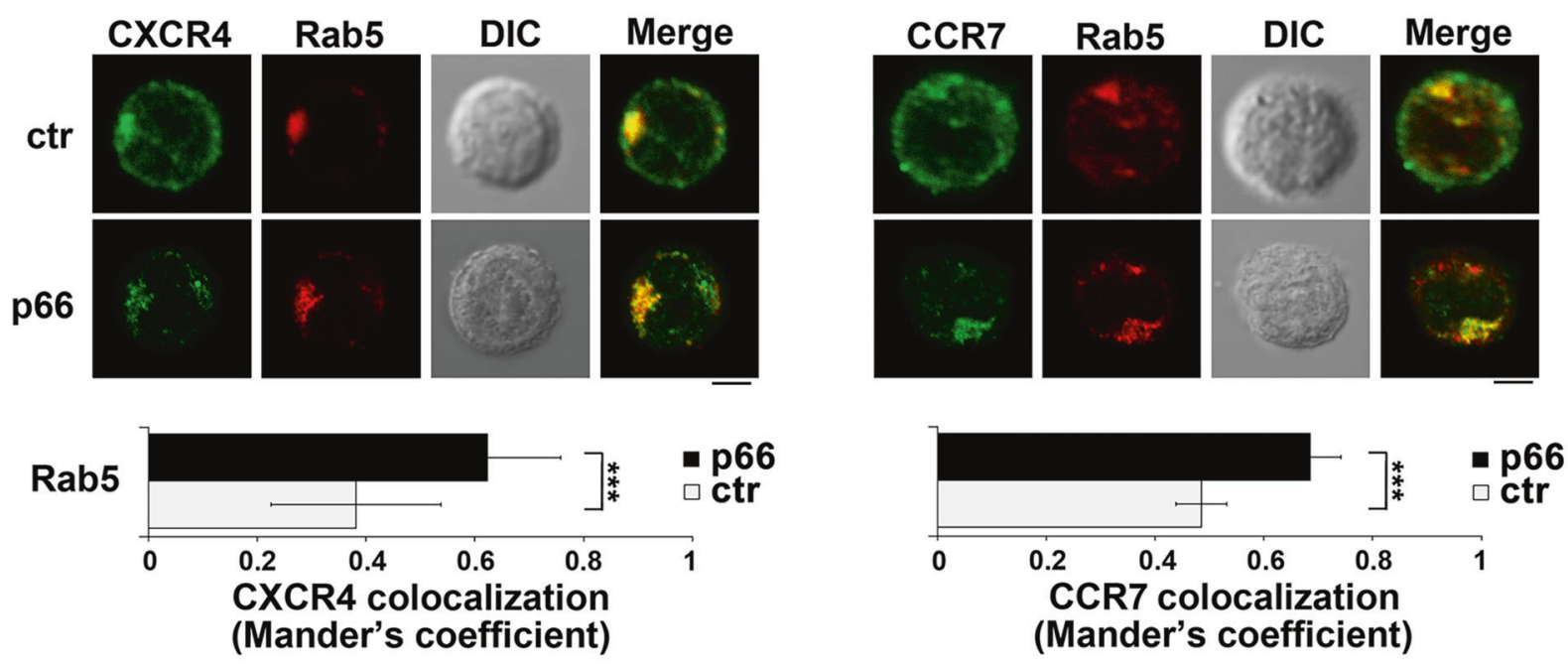

b
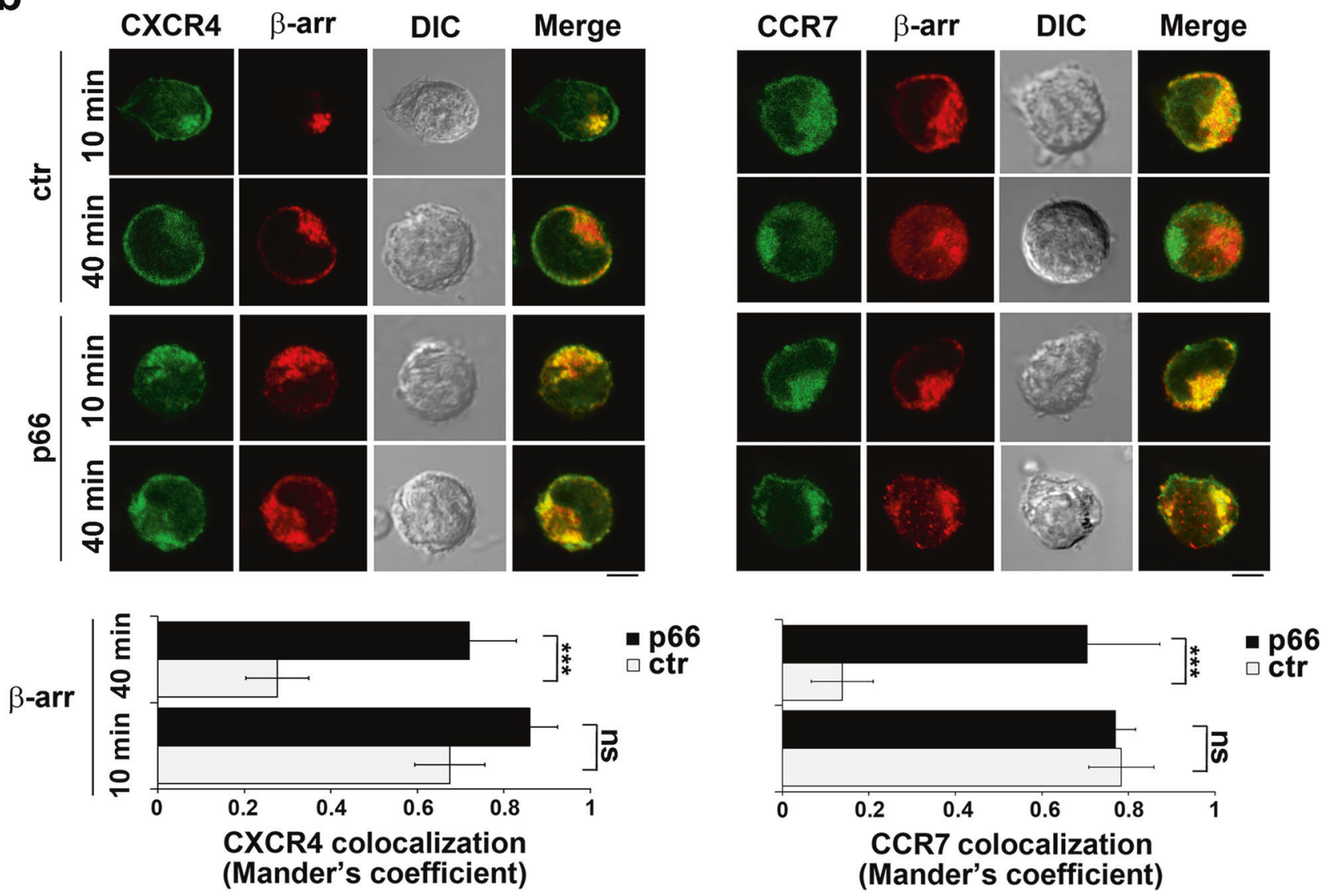

Fig. 2 p66Shc expression enhances CXCR4/CCR7 colocalization with Rab5 and $\beta$-arrestin in MEC B cells. a Immunofluorescence analysis of Rab5 (red) and either CXCR4 (green, left) or CCR7 (green, right) in ctr and p66 MEC B cells incubated with $100 \mathrm{ng} / \mathrm{ml}$ of CXCL12/ CCL2 1 at $37^{\circ} \mathrm{C}$ for $40 \mathrm{~min}$, fixed and permeabilized. Representative median optical sections are shown. The quantification using Mander's coefficient of the weighted colocalization of CXCR4 (left) or CCR7 (right) with Rab5 in individual medial confocal sections is shown below the corresponding images $(n=3)$. b Immunofluorescence analysis of $\beta$-arrestin (red) and either CXCR4 (green, left) or CCR7

(green, right) in ctr and p66 MEC B cells incubated with $100 \mathrm{ng} / \mathrm{ml}$ of CXCL12/CCL21 at $37{ }^{\circ} \mathrm{C}$ for either 10 or $40 \mathrm{~min}$, fixed and permeabilized. Representative median optical sections are shown. The quantification using Mander's coefficient of the weighted colocalization of CXCR4 (left) or CCR7 (right) with $\beta$-arrestin in individual medial confocal sections is shown below the corresponding images ( $n$ $=3$ ). Representative median optical sections are shown. Size bar, 5 $\mu \mathrm{m}$, mean $\pm \mathrm{SD} ; \geq 20$ cells per marker. Error bars, SD. Student's $t$-test (unpaired). $* * * p<0.001$ 
Fig. 3 p66Shc stabilizes the interaction of CXCR4/CCR7 with Rab5 and $\beta$-arrestin in MEC B cells. a Immunoblot analysis with anti- $\beta$-arrestin and anti-Rab5 antibodies of CXCR4specific (left) and CCR7-specific (right) immunoprecipitates from lysates of ctr and p66 MEC B cells, either unstimulated or activated with either $500 \mathrm{ng} / \mathrm{ml}$ CXCL12 or $1 \mu \mathrm{g} / \mathrm{ml}$ CCL21. The stripped filters were reprobed with anti-CXCR4 or antiCCR7 antibodies. The quantification of the relative amount of $\beta$-arrestin and Rab5 is indicated below the respective immunoblots. b Immunoblot analysis with anti- $\beta$-arrestin, -Rab5, -CXCR4 and -CCR7 antibodies of $\mathrm{CH} 2$-specific immunoprecipitates from lysates of p66 MEC B cells, either unstimulated or activated with either $500 \mathrm{ng} / \mathrm{ml}$ CXCL12 or $1 \mu \mathrm{g} / \mathrm{ml}$ CCL21. The stripped filters were reprobed with anti-Shc antibodies. The quantification of the relative amount of Rab5 and $\beta$-arrestin co-immunoprecipitated with p66She is shown on the right. The migration of molecular mass markers is indicated. The immunoblots shown in the figure are representative of three independent experiments. Error bars, SD. Student's $t$-test (unpaired). $* * p<0.01 ; * p<0.05$ a
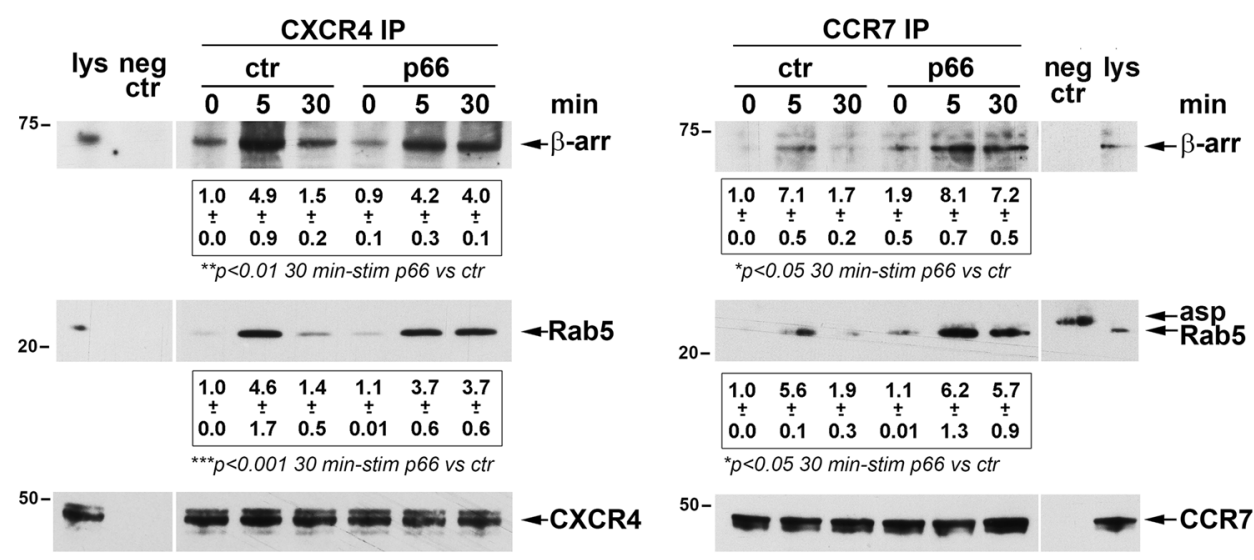

$50-\square-C$ CRR7

b

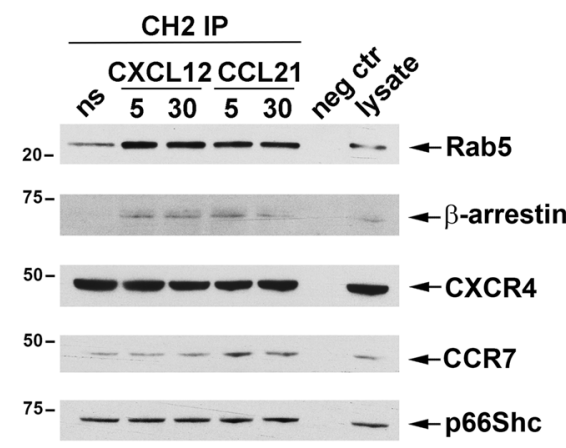

Rab5 and $\beta$-arrestin (Fig. 4c). Hence, p66Shc deficiency leads to a reduction in CXCR4/CCR7 accumulation in early endosomes in CLL cells, accounting for their faster recycling.

\section{p66Shc inhibits CXCR4 and CCR7 recycling by impairing their PP2B-dependent dephosphorylation}

GPCR traffic from $\mathrm{Rab5}^{+}$endosomes requires their dephosphorylation-dependent $\beta$-arrestin release [21]. As p66Shc inhibits CXCR4/CCR7 recycling by promoting their accumulation in $\mathrm{Rab}^{+}$endosomes in association with $\beta$-arrestin, we hypothesized that dephosphorylation of these receptors might be impaired in the presence of p66Shc. CXCR4/CCR7 were immunoprecipitated from the MEC transfectants stimulated with the respective ligands at two different time points. Serine phosphorylation of both receptors was found to increase above basal levels in both ctr and p66Shc-expressing cells early after stimulation (Fig. 5a). CXCR4 phosphorylation was found to depend on the activity of both $\mathrm{G}$ protein-coupled receptor kinases (GRKs) and protein kinase $\mathrm{C}$ (PKC), but not protein kinase A (PKA), whereas CCR7 phosphorylation requires only GRKs, as demonstrated by pre-treating MEC cells with the non-selective GRK family inhibitor 4-amino-5-(bromomethyl)-2-methylpyrimidine hydrobromide [22], or the nonselective PKC family inhibitor bisindolylmaleimide-1hydrochloride [23], or the PKA inhibitor H89 [24] (Supplementary Figure 6a). Interestingly, although CXCR4/ CCR7 phosphorylation decreased at longer times in ctr cells, consistent with their re-exposure at the plasma membrane, it remained almost unchanged in p66Shcexpressing cells (Fig. 5a). This was confirmed for CXCR4 by flow cytometric analysis using an anti-phosphoserine339 antibody (Supplementary Figure 7a). Consistent with the results obtained on the MEC transfectants, CXCR4 was transiently phosphorylated in response to CXCL12 in CLL cells as opposed to the sustained phosphorylation in primary 
a

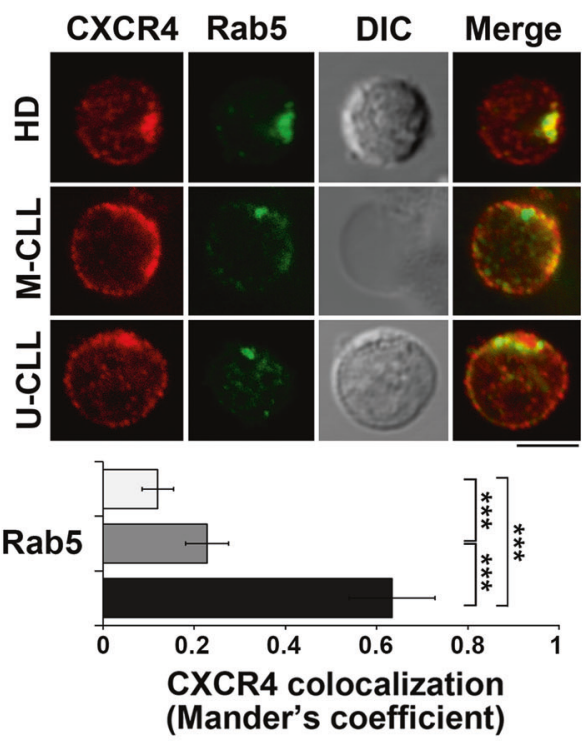

b

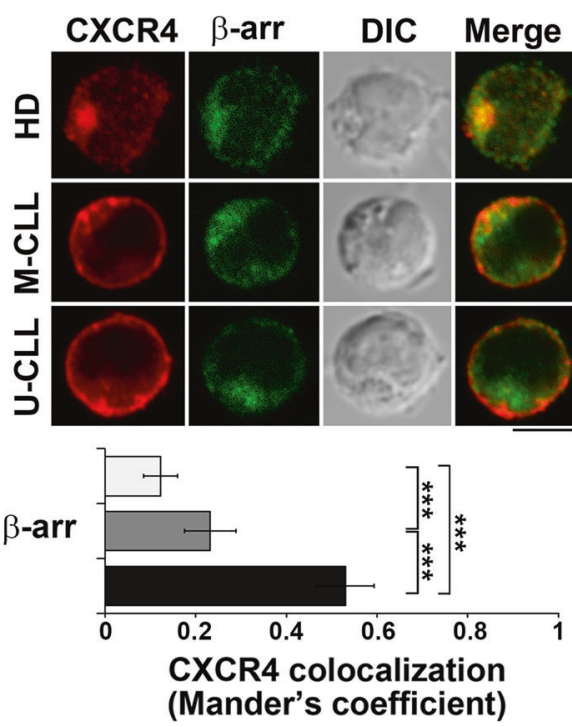

C

- CLL p66 (n=13)

$\square$ CLL vect $(n=13)$

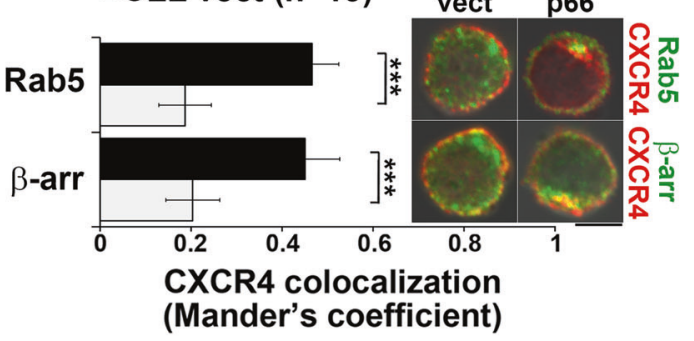

Fig. 4 p66Shc reconstitution in CLL B cells enhances CXCR4/CCR7 colocalization with Rab5 and $\beta$-arrestin. a, b Immunofluorescence analysis of Rab5 (green) a or $\beta$-arrestin (green) $\mathbf{b}$, and either CXCR4 (red) or CCR7 (red) in B cells purified from healthy donors (HD, $n=15)$ and from M-CLL $(n=17)$ or U-CLL $(n=15)$ patients, incubated with 100 $\mathrm{ng} / \mathrm{ml}$ of CXCL12/CCL21 at $37^{\circ} \mathrm{C}$ for $40 \mathrm{~min}$, fixed and permeabilized. Size bar, $5 \mu \mathrm{m}$. The quantification using Mander's coefficient of the weighted colocalization of CXCR4 (left) or CCR7 (right) with Rab5 and $\beta$-arrestin in individual medial confocal sections is shown below the
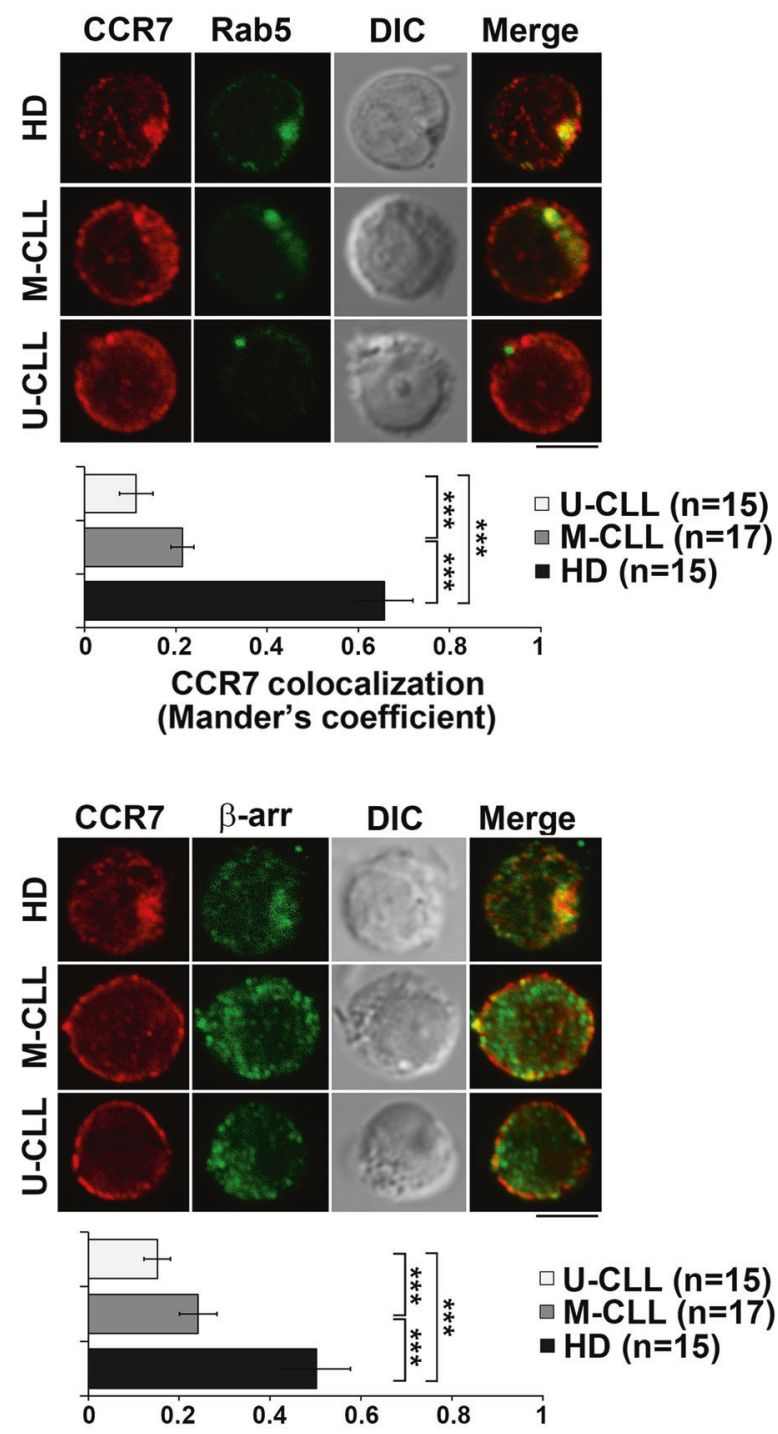

CCR7 colocalization

(Mander's coefficient)

- CLL p66 (n=13)

$\square$ CLL vect $(n=13)$

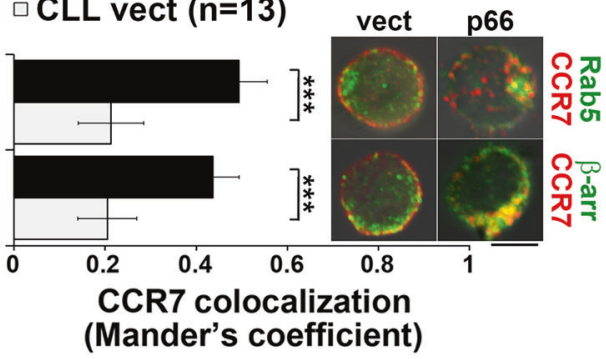

corresponding images. c Quantification using Mander's coefficient of the weighted colocalization of CXCR4 (left) or CCR7 (right) with Rab5 and $\beta$-arrestin in individual medial confocal sections of purified CLL B cells $(n=13)$, nucleofected with either empty vector (ctr) or an expression construct encoding p66Shc (p66), incubated with $100 \mathrm{ng} / \mathrm{ml}$ of CXCL12/ CCL2 1 at $37^{\circ} \mathrm{C}$ for 40 min, fixed and permeabilized (mean $\pm \mathrm{SD} ; \geq 30$ cells per marker per donor or CLL patient). Representative median optical sections are shown. Size bar, $5 \mu \mathrm{m}$. Error bars, SD. Mann-Whitney rank sum test (unpaired). $* * * p<0.001$ 
a

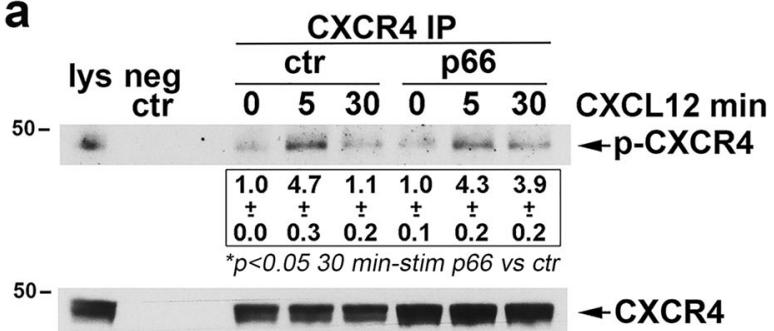

b

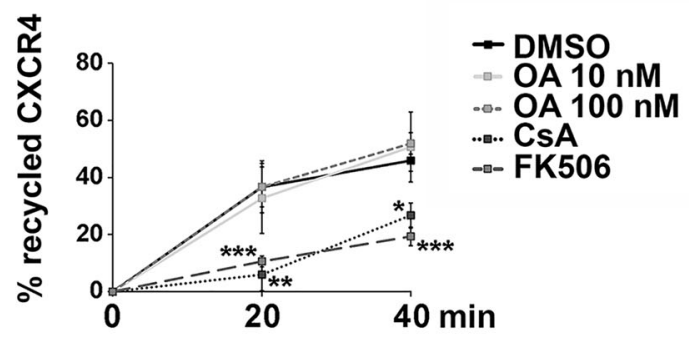

C

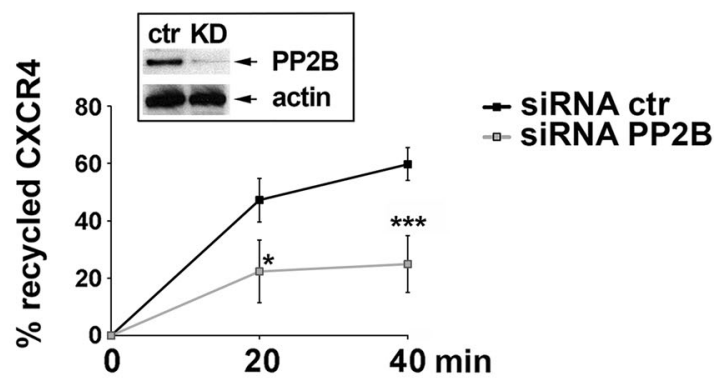

d

SiRNA ctr PP2B KD

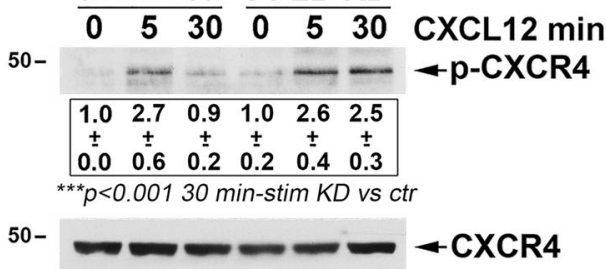

e

CXCR4 IP

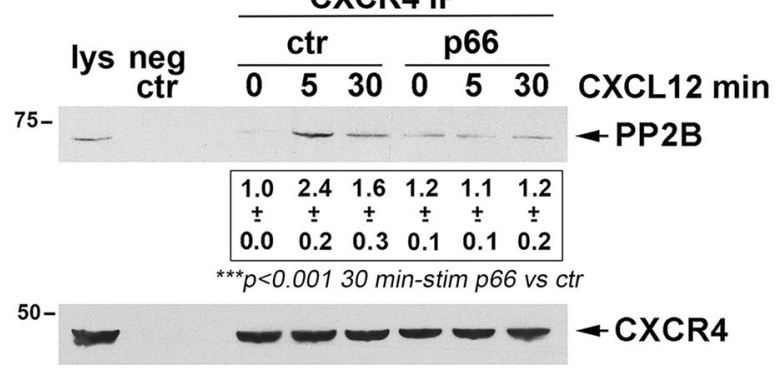

B cells from healthy donors (Supplementary Figure 7b). This abnormality was reversed by forced p66Shc expression (Supplementary Figure 7c). Hence, p66Shc prolongs the
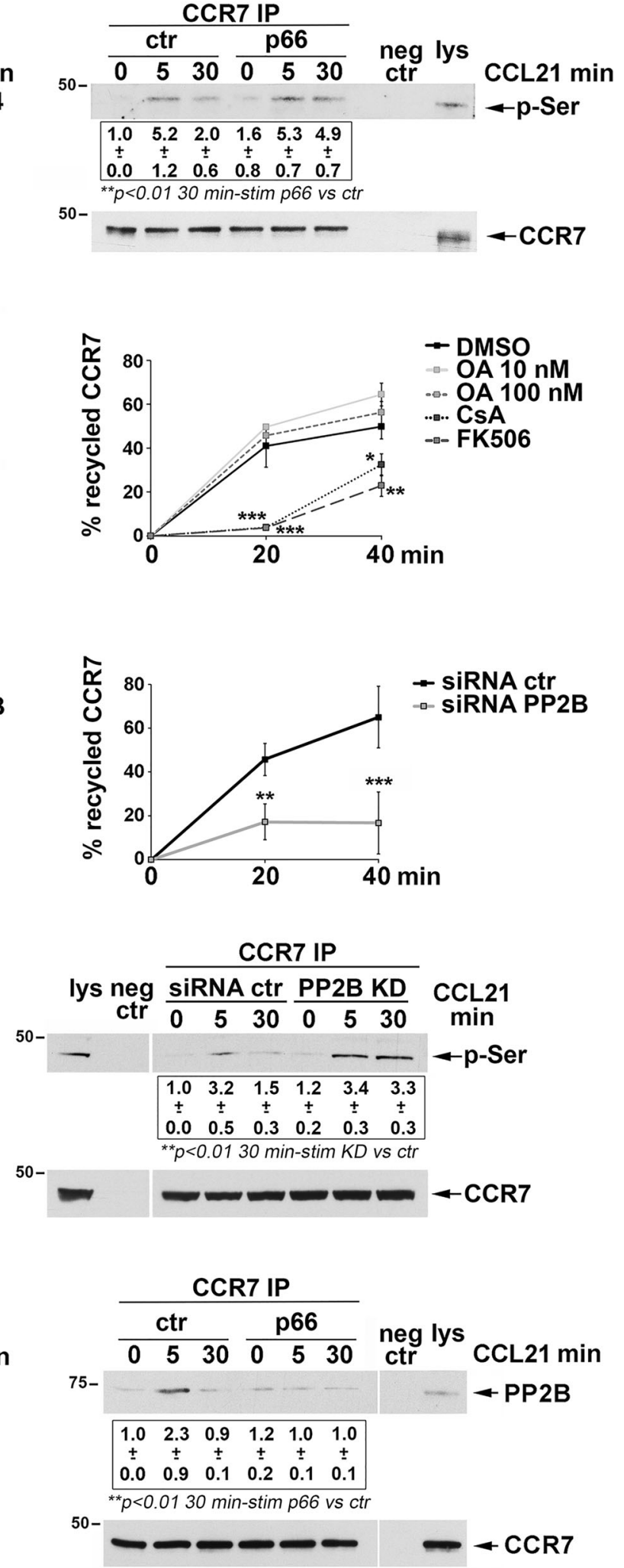

interaction of CXCR4/CCR7 with $\beta$-arrestin and hence their residency in early endosomes by inhibiting their dephosphorylation. 
Fig. 5 p66Shc inhibits PP2B-dependent dephosphorylation of CXCR4 and CCR7. a Immunoblot analysis with anti-phospho-CXCR4 or antiphosphoserine antibodies of either CXCR4-specific (left) or CCR7specific (right) immunoprecipitates from lysates of ctr and p66 MEC B cells, either unstimulated or activated for 5 and $30 \mathrm{~min}$ with either 500 $\mathrm{ng} / \mathrm{ml} \mathrm{CXCL12}$ or $1 \mu \mathrm{g} / \mathrm{ml}$ CCL21. The stripped filters were reprobed with anti-CXCR4 or anti-CCR7 antibodies. b Flow cytometric analysis of CXCR4/CCR7 recycling in ctr MEC B cells incubated for $30 \mathrm{~min}$ at $37^{\circ} \mathrm{C}$ with DMSO, 10 and $100 \mathrm{nM}$ okadaic acid (OA), $1 \mu \mathrm{M}$ CsA, or $1 \mu \mathrm{M}$ FK506. Data are presented as $\%$ of internalized receptors that have recycled to the cell surface at the indicated times and refer to duplicate samples from three independent experiments. c Flow cytometric analysis of CXCR4/CCR7 recycling in ctr MEC B cells transiently transfected with $1 \mu \mathrm{g}$ of either ctr siRNA (RLUC) or siRNA for PP2BCA (residual PP2BCA: 20\%). A construct encoding GFP under the control of a constitutive promoter was included in each transfection as a control. Analyses were carried out at $48 \mathrm{~h}$ post-transfection, gating on $\mathrm{GFP}^{+}$live cells. Data are presented as \% of internalized receptors that have recycled to the cell surface at the indicated times and refer to duplicate samples from three independent experiments. d Immunoblot analysis with anti-phospho-CXCR4 (left) or anti-phosphoserine antibodies (right) of lysates (left) or CCR7-specific immunoprecipitates from lysates (right) of ctr MEC B cells, transiently transfected with 1 $\mu \mathrm{g}$ of either ctr siRNA (RLUC) or siRNA for PP2BCA (residual PP2BCA: 20\%) and either unstimulated or activated for 5 and $30 \mathrm{~min}$ with either $500 \mathrm{ng} / \mathrm{ml} \mathrm{CXCL12} \mathrm{or} 1 \mu \mathrm{g} / \mathrm{ml} \mathrm{CCL21.} \mathrm{The} \mathrm{stripped} \mathrm{filters}$ were reprobed with anti-CXCR4 or anti-CCR7 antibodies. e Immunoblot analysis with anti-PP2B antibodies of either CXCR4-specific (left) or CCR7-specific (right) immunoprecipitates from lysates of ctr and p66 MEC B cells, either unstimulated or activated for 5 and 30 min with either $500 \mathrm{ng} / \mathrm{ml} \mathrm{CXCL12} \mathrm{or} 1 \mu \mathrm{g} / \mathrm{ml}$ CCL21. The stripped filters were reprobed with anti-CXCR4 or anti-CCR7 antibodies. The quantification of the relative protein amount is indicated below the respective immunoblots. The immunoblots shown in the figure are representative of three independent experiments. Error bars, SD. Student's $t$-test (unpaired). $* * * p<0.001 ; * * p<0.01 ; * p<0.05$

The phosphoserine phosphatase responsible for CXCR4/ CCR7 dephosphorylation is unknown. We reasoned that pharmacological inhibitors that would phenocopy the effects of p66Shc expression would provide clues to the identity of this phosphatase. CXCR4/CCR7 recycling was analyzed in ctr MEC cells pretreated with inhibitors of phosphatases known to be implicated in recycling of other GPCRs. We used $10 \mathrm{nM}$ okadaic acid to inhibit PP2A [25], $100 \mathrm{nM}$ okadaic acid to inhibit PP1 and PP2A [26], and 1 $\mu \mathrm{M}$ CsA or FK506 to inhibit PP2B (also known as calcineurin) [27]. PP1 and PP2A inhibitors did not affect CXCR4/CCR7 recycling. Conversely, a profound inhibition was observed in the presence of CsA or FK506 (Fig. 5b), implicating PP2B in CXCR4 and CCR7 dephosphorylation. This notion was supported by the prolonged phosphorylation of CXCR4/CCR7 observed in ctr MEC cells pretreated with CsA or FK506 and stimulated with the respective ligands (Supplementary Figure $6 \mathrm{~b}$ and $\mathrm{c}$ ). These results were recapitulated by knocking-down PP2BCA, the catalytic subunit of $\mathrm{PP} 2 \mathrm{~B}$, in ctr MEC cells, which resulted in a profound inhibition of CXCR4/CCR7 recycling (Fig. 5c) and their prolonged phosphorylation in response to the respective ligands (Fig. 5d).

Interestingly, PP2B was found to interact with both CXCR4 and CCR7 in the MEC transfectants. This interaction was enhanced in response to the respective chemokines early after stimulation in both transfectants (Fig. 5e). Although the amount of PP2B co-immunoprecipitated with CXCR4/CCR7 decreased at a longer stimulation time in ctr MEC cells, concomitant with their dephosphorylation (Fig. 5a), this did not occur in p66-expressing cells (Fig. 5e). These data implicate PP2B in CXCR4/CCR7 dephosphorylation and suggest that $\mathrm{PP} 2 \mathrm{~B}$ is subsequently released to allow their recycling to the plasma membrane.

\section{p66Shc inhibits CXCR4/CCR7-dependent PP2B activation by suppressing $\mathrm{Ca}^{2+}$ flux}

To elucidate the mechanism underlying the inhibition of PP2B-dependent CXCR4/CCR7 dephosphorylation by p66Shc we tested the expression and activity of PP2B in the MEC transfectants. PP2B expression was not affected by p66Shc (Fig. 6a). Based on the $\mathrm{Ca}^{2+}$ dependence of PP2B [24] and the ability of p66Shc to attenuate CXCR4/ CXCR5 signaling [20], we analyzed CXCL12/CCL21induced $\left[\mathrm{Ca}^{2+}\right]_{\mathrm{i}}$ mobilization. Chemokine stimulation of ctr MEC cells triggered a $\left[\mathrm{Ca}^{2+}\right]_{i}$ elevation, which was strongly impaired in the p66Shc-expressing transfectant (Fig. 6a and Supplementary Figure 8a), suggesting that p66Shc may inhibit PP2B activation by blocking CXCR4/CCR7dependent $\mathrm{Ca}^{2+}$ mobilization. To assess this possibility, we transiently transfected ctr and p66Shc-expressing MEC cells with a reporter encoding green fluorescent protein (GFP)-tagged nuclear factor of activated T cells (NFAT), a transcription factor that requires PP2B-mediated dephosphorylation for nuclear translocation [28], and scored the number of cells harboring nuclear NFAT-GFP following CXCL12 or CCL21 stimulation. Both chemokines triggered nuclear translocation of NFAT-GFP in ctr MEC cells, which was impaired in the p66Shc-expressing transfectant (Fig. 6c). Of note, we did not observe any significant effect of p66Shc overexpression on chemokine-mediated apoptosis, as assessed by AnnexinV/propidium iodide staining, ruling out the possibility that p66Shc could impair cell viability, at least early after chemokine stimulation (Supplementary Figure 9). Hence, p66Shc inhibits PP2B activation by impairing chemokine-dependent $\left[\mathrm{Ca}^{2+}\right]_{\mathrm{i}}$ mobilization, supporting the notion that the sustained phosphorylation of CXCR4/CCR7 in p66Shc-expressing cells results from defective PP2B activation.

Consistent with these results, B cells from CLL patients displayed an enhancement in CXCL12- and CCL21dependent $\left[\mathrm{Ca}^{2+}\right]_{i}$ mobilization (Fig. 6e and Supplementary Figure $8 \mathrm{~b}$ ) and NFAT-GFP nuclear translocation (Fig. 
a

$$
\begin{aligned}
& 0^{5} e^{6^{6}} \\
& -- \text { PP } 2 B \\
& -- \text { actin }
\end{aligned}
$$

b
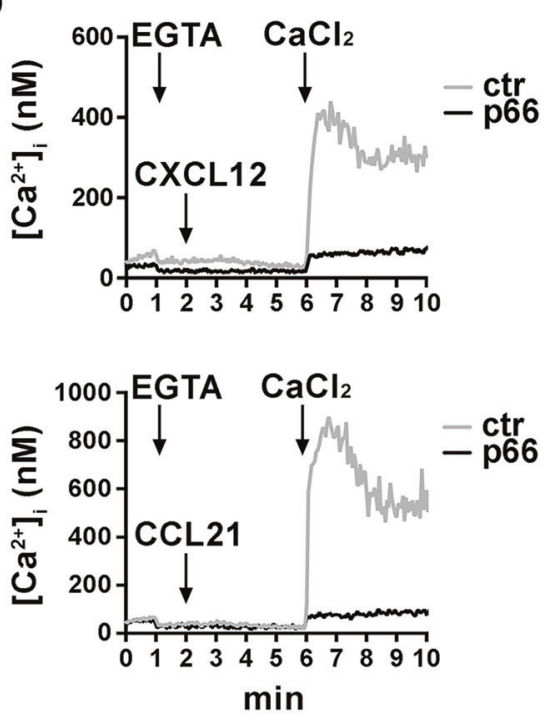

d

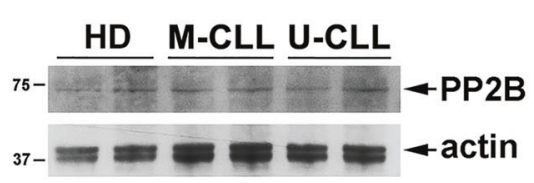

e
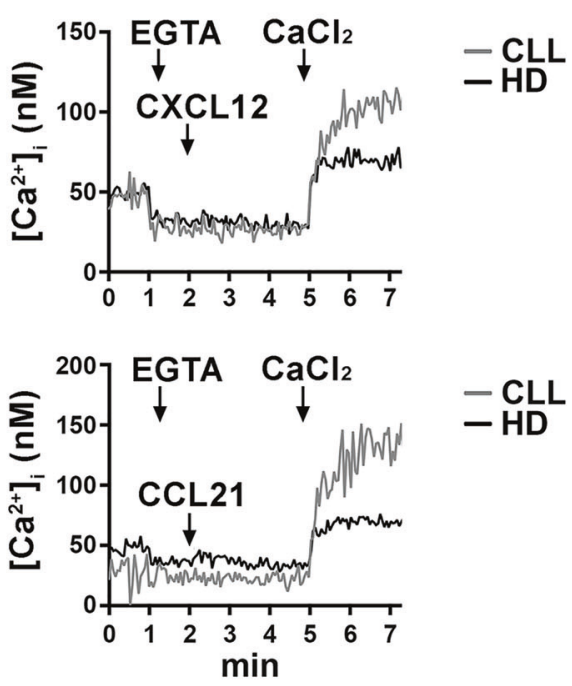

C
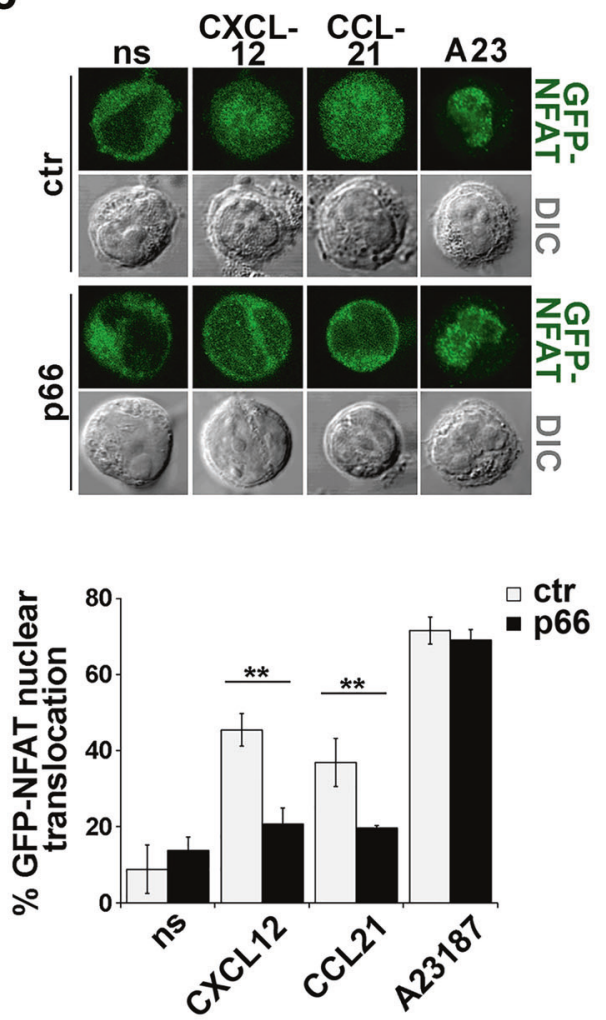

f
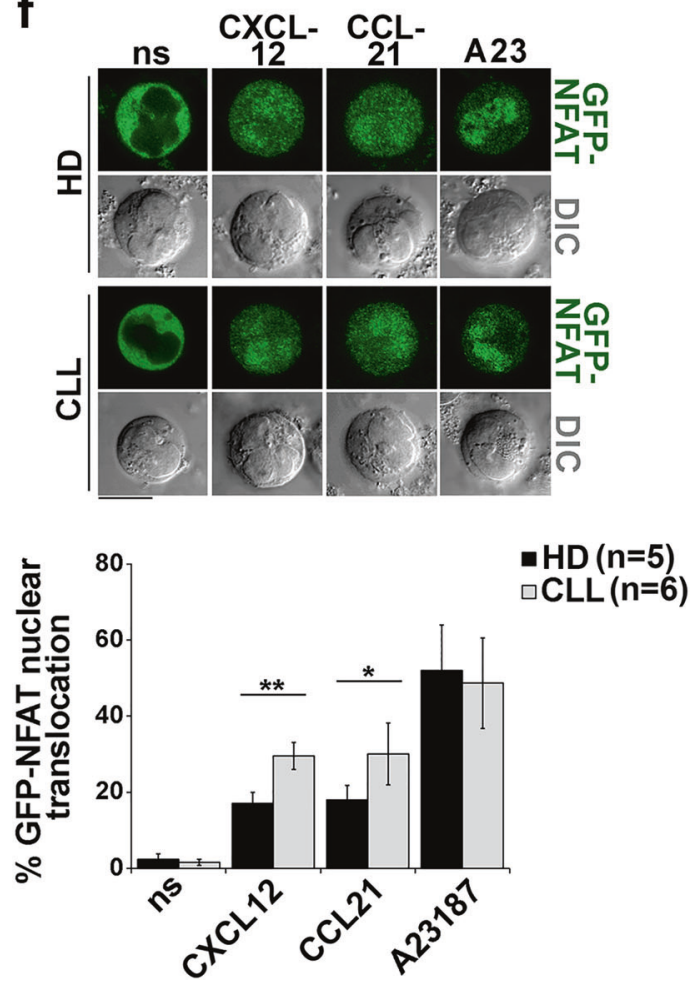
Fig. 6 p66Shc inhibits CXCR4/CCR7-dependent PP2B activation. a, d Immunoblot analysis with anti-PP2B antibodies of postnuclear supernatants from ctr and p66 MEC B cells a or from purified healthy donor (HD), M-CLL or U-CLL B cells d. The stripped filters were reprobed with anti-actin antibodies. b Fluorimetric analysis of $\left[\mathrm{Ca}^{2+}\right]_{\mathrm{i}}$ in ctr and p66 MEC B cells stimulated with $100 \mathrm{ng} / \mathrm{ml}$ of CXCL12/ CCL21. The arrow indicates the time of addition of chemokines, $1 \mathrm{mM}$ EGTA and $1 \mathrm{mM} \mathrm{CaCl}_{2}$, respectively. The total levels of storeassociated $\mathrm{Ca}^{2+}$, as measured after cell solubilization by digitonin treatment in the presence of EGTA, were similar in all cell lines. Representative experiments are shown $(n=3)$. c Confocal microscopy of ctr and p66 MEC B cells transiently transfected with a GFP-NFAT expression construct, either unstimulated (ns) or stimulated with 100 $\mathrm{ng} / \mathrm{ml} \mathrm{CXCL12}$ or CCL21 for $1 \mathrm{~h}$ or with $500 \mathrm{ng} / \mathrm{ml} \mathrm{A23187} \mathrm{(A23)} \mathrm{for}$ $20 \mathrm{~min}$. The percentage of cells displaying nuclear GFP-NFAT was calculated by analyzing at least 100 cells per sample $(n=3)$. e Fluorimetric analysis of $\left[\mathrm{Ca}^{2+}\right]_{\mathrm{i}}$ in purified HD or CLL B cells stimulated with $100 \mathrm{ng} / \mathrm{ml} \mathrm{CXCL12}$ or CCL21. The total levels of storeassociated $\mathrm{Ca}^{2+}$ were similar in all samples (data not shown). Representative experiments are shown $(\mathrm{HD}=11, \mathrm{CLL}=10)$. f Confocal microscopy of purified HD or CLL B cells transiently transfected with a GFP-NFAT expression construct, either unstimulated (ns) or stimulated with $100 \mathrm{ng} / \mathrm{ml}$ of CXCL12 or CCL21 for $1 \mathrm{~h}$ or with $500 \mathrm{ng} /$ $\mathrm{ml} \mathrm{A} 23$ for $20 \mathrm{~min}$. The percentage of cells displaying nuclear GFPNFAT was calculated by analyzing at least 100 cells per sample (HD $=5$, M-CLL $=6$ ). Error bars, SD. Student's $t$-test (unpaired). $* * p<0.01 ; * p<0.05$

6f) compared with healthy donor B cells while expressing comparable PP2B levels (Fig. 6d). These data support the inhibitory role of p66Shc in PP2B-mediated CXCR4/CCR7 dephosphorylation and provide a mechanism for the recycling defect in CLL cells.

\section{Ibrutinib normalizes CXCR4 and CCR7 recycling by enhancing p66Shc expression}

Treatment of CLL patients with ibrutinib, a Btk inhibitor used in clinical trials alone or in combination with conventional chemotherapeutic drugs [29, 30], results in massive leukemic cell mobilization from lymph nodes paralleled by a transient lymphocytosis [31]. We found that ibrutinib corrects the imbalance between homing and egress receptors in CLL cells in vitro and in vivo by modulating CCR7 and S1PRI expression [11] (Supplementary Figure $10)$, which is expected to promote leukemic cell exit from the pro-survival stromal niche [31-34].

As p66Shc modulates CCR7 and S1PR1 expression [13], we hypothesized that these effects of ibrutinib could be accounted for by enhanced p66Shc expression. Ibrutinib treatment of CLL cells resulted indeed in a robust dosedependent increase in p66Shc expression, as measured by quantitative reverse transcriptase-PCR (Fig. 7a and Supplementary Figure 11a). A significant in vivo upregulation of p66Shc expression was also observed in CLL cells from patients administered daily for 4 months with ibrutinib (Fig. 7a).
Consistent with the inhibitory effects of p66Shc on CXCR4/CCR7 recycling, ibrutinib-treated CLL cells displayed a reduction in CXCR4/CCR7 recycling (Fig. 7b) and their subcellular distribution became largely intracellular (Fig. 7c) resulting in a dose-dependent decrease in the ratio of surface-to-total receptors (Fig. 7d and Supplementary Figure 11b-e). Ibrutinib treatment restored moreover CXCR4/CCR7 colocalization of with Rab5 and $\beta$-arrestin in CLL cells (Fig. 7e). These results further support a role for p66Shc as a central regulator of CXCR4/CCR7 transit throughout the recycling route.

\section{Discussion}

Beside gene transcription [13], receptor recycling is an important determinant in controlling the levels of surface chemokine receptors and downstream responses in CLL [11]. Here we implicate the p66Shc defect harbored by CLL cells [19] in the abnormal recycling on which elevated surface CXCR4/CCR7 expression largely depends. We show indeed that p66Shc negatively regulates CXCR4/ CCR7 recycling by inhibiting the $\mathrm{Ca}^{2+}$-dependent activation of the phosphatase PP2B that we identify as responsible for their dephosphorylation. This results in the accumulation of the internalized $\beta$-arrestin-bound receptors in Rab5 ${ }^{+}$ endosomes and hence their failure to transit to recycling endosomes. We provide moreover novel insights into the molecular mechanisms that underlie the therapeutic effects of ibrutinib in CLL by showing that it targets homing receptor recycling, normalizing the surface levels and subcellular distribution of CXCR4/CCR7 in CLL cells by upregulating p66Shc expression.

Chemokine-dependent signaling is rapidly modulated post-translationally by receptor internalization and recycling. The mechanism regulating CXCR4 and CCR7 recycling has been partly elucidated in cell types other than Blymphocytes, where it has been shown to require $\beta$-arrestin binding to the serine-phosphorylated cytosolic tail, internalization and transport to $\mathrm{Rab}^{+}$endosomes [16-18, 3540]. Similar to other GPCRs [21, 41], $\beta$-arrestin release through dephosphorylation is required for chemokine receptor transit from early-to-recycling endosomes [16, 17, 39]. Our results show that, while internalized CXCR4 is preferentially targeted to late endosomes and CCR7 to recycling endosomes in other cell types [16, 17, 42], these receptors appear to follow the same route in $\mathrm{B}$ cells, both undergoing recycling through a pathway involving dephosphorylation-dependent $\beta$-arrestin release at Rab5positive early endosomes. We have identified PP2B as the phosphatase shared by CXCR4 and CCR7, with which it interacts, for this step. 


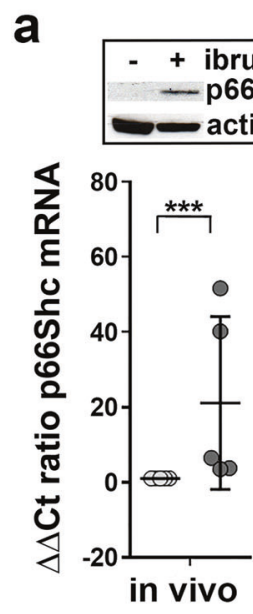

C
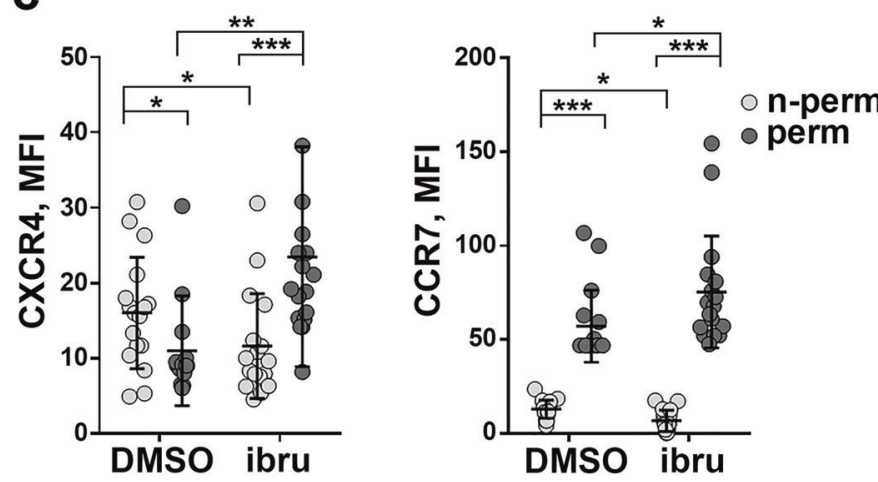
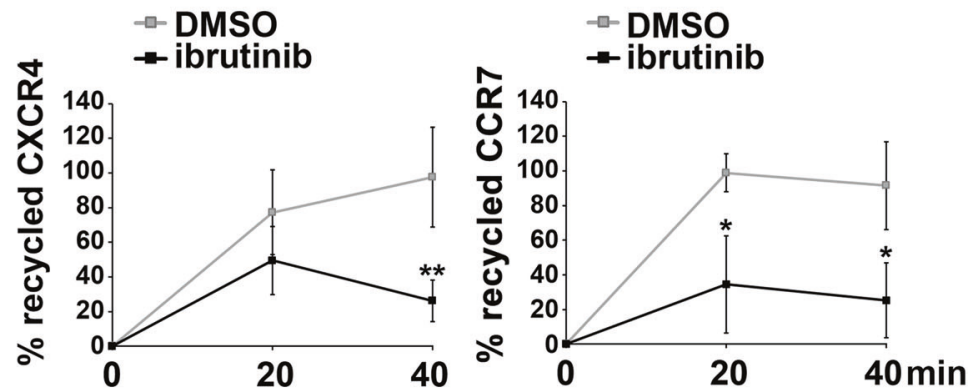

e

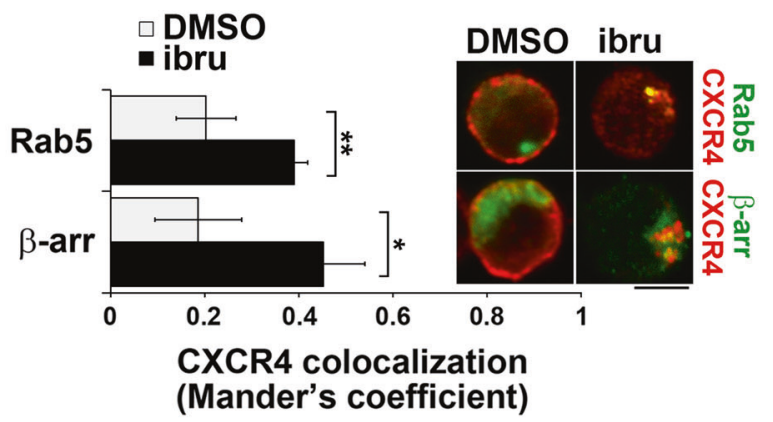

Fig. 7 Ibrutinib promotes p66Shc expression in CLL cells and normalizes CXCR4 and CCR7 recycling. a Bottom, quantitative RT-PCR analysis of p66Shc mRNA either on purified peripheral B cells from five CLL patients with lymphadenopathy, before (pre) and after (post) 4-month in vivo ibrutinib treatment, or on B cells from 23 CLL patients treated in vitro with either DMSO or $10 \mu \mathrm{M}$ ibrutinib for $48 \mathrm{~h}$. The relative gene transcript abundance was determined on triplicate samples using the ddCt method (fold change in samples post- versus pre-treatment). Top, immunoblot analysis with anti-Shc antibodies of CLL cells treated or untreated with ibrutinib, as above. The stripped filter was reprobed with anti-actin antibodies. b Flow cytometric analysis of CXCR4/CCR7 recycling in purified CLL B cells treated in vitro with either DMSO or $10 \mu \mathrm{M}$ ibrutinib for $48 \mathrm{~h}$. Data are presented as $\%$ of internalized receptors that have recycled to the cell surface and refer to duplicate samples $(n=4)$. c Flow cytometric d
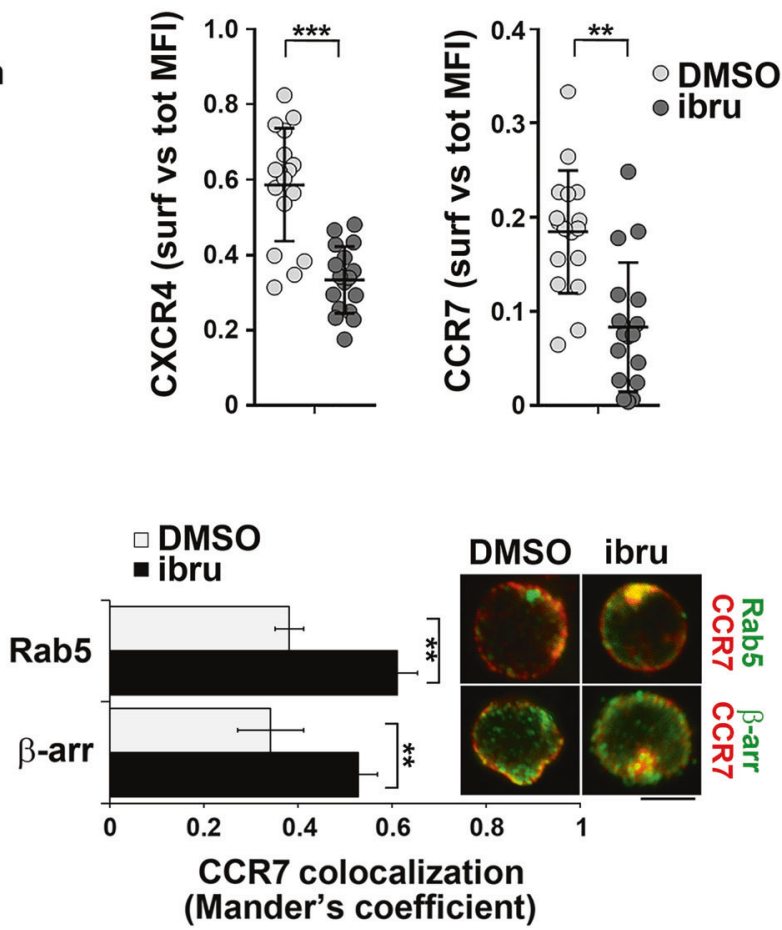

analysis of CXCR4 or CCR7 on purified CLL B cells treated in vitro with either DMSO or $10 \mu \mathrm{M}$ ibrutinib for $48 \mathrm{~h}$, either nonpermeabilized (n-perm) or permeabilized (perm). d Ratio of surfaceto-total MFI of CXCR4 and CCR7 from CLL B cells treated in vitro with either DMSO or $10 \mu \mathrm{M}$ ibrutinib for $48 \mathrm{~h}$. Data are expressed as ratio of MFI in non-permeabilized cells (surface) to permeabilized (total) cells. e Quantification using Mander's coefficient of the weighted colocalization of CXCR4 or CCR7 with Rab5 and $\beta$-arrestin in individual medial confocal sections of purified CLL B cells $(n=5)$ treated in vitro with either DMSO or $10 \mu \mathrm{M}$ ibrutinib for $48 \mathrm{~h}$, incubated with $100 \mathrm{ng} / \mathrm{ml}$ of CXCL12/CCL2 1 at $37^{\circ} \mathrm{C}$ for $40 \mathrm{~min}$, fixed and permeabilized. Representative median optical sections are shown on the right (mean $\pm \mathrm{SD} ; \geq 20$ cells per marker). Size bar, $5 \mu \mathrm{m}$. Error bars, SD. Mann-Whitney rank sum test (unpaired). ${ }^{* * *} p<0.001$; $* * p<0.01 ; * p<0.05$ 
Several GPCRs colocalize with Rab5 and rely on its GTPase activity for their internalization and traffic [43]. A role for membrane receptors in regulating their own traffic through recruitment and activation of components of the Rab-based traffic machinery has been demonstrated in very few instances, which include the polymeric $\operatorname{IgA}$ receptor and the GPCR AT1AR, which interact with Rab3b and Rab5, respectively [44, 45]. Other GPCRs are indirectly coupled to Rab5 through interactors that are beginning to be identified. One example is CXCR4, which has been recently shown to require the protein missing-in-metastasis for ligand-dependent internalization and Rab5 binding in HeLa cells [46]. Our data demonstrate the existence of a multimolecular complex, which includes CXCR4/CCR7, $\beta$ arrestin, Rab5 and PP2B and is stabilized by p66Shc. Whether Rab5 interacts directly or indirectly with these receptors in B cells, which are the reciprocal interactions among the components of the complex, and how p66Shc prolongs its half-life are questions that remain to be clarified.

p66Shc inhibits CXCR4- and CXCR5-dependent signaling by interacting with these receptors to promote the assembly of an inhibitory complex containing the phosphatases SHP-1 and SHIP-1, which results in impaired spleen tyrosine kinase (Syk) and Btk phosphorylation [20]. Both kinases contribute to BCR-dependent PLC- $\gamma 2$ activation, which in turn initiates inositol-1,4,5-tris-phosphatedependent $\left[\mathrm{Ca}^{2+}\right]_{\mathrm{i}}$ mobilization [47]. Here we show a major defect of chemokine-dependent $\left[\mathrm{Ca}^{2+}\right]_{\mathrm{i}}$ mobilization in p66Shc-expressing B cells, which could be accounted for by impaired Syk and Btk phosphorylation. This defect is likely to underlie the defect in PP2B activation, which is dependent on $\mathrm{Ca}^{2+}$-calmodulin, resulting in the failure of CXCR4/CCR7 to become dephosphorylated and hence in their endosomal accumulation. The fact that p66Shc modulates CXCR5 signaling [20] raises the possibility that the p66Shc-dependent and PP2B-mediated regulation of endosome recycling may extend to this homing receptor, which controls local B-cell traffic in SLOs and, similar to CCR7 and CXCR4, is overexpressed at the surface of CLL B cells [48].

Emerging evidence indicates that surface receptors continue signaling at endosomes following ligand-dependent internalization [49]. This may compartmentalize signaling to specific subcellular localizations, as shown for endosomal $\beta$-2 adrenergic receptors [50]. The finding that serinephosphorylated CXCR4/CCR7 are found at $\mathrm{Rab}^{+}$endosomes in association with $\beta$-arrestin and $\mathrm{PP} 2 \mathrm{~B}$ suggests that PP2B is activated locally to dephosphorylate the receptors, allowing their transit to recycling endosomes. This could be achieved through $\left[\mathrm{Ca}^{2+}\right]_{\mathrm{i}}$ mobilization by endosomal CXCR4/CCR7. The tight packing of membrane compartments within the scant B-cell cytosol is expected to allow
$\left[\mathrm{Ca}^{2+}\right]_{\mathrm{i}}$ mobilization close to endosomes carrying signaling CXCR4/CCR7 from neighboring endoplasmic reticulum and/or mitochondria. This process would be impaired in the presence of p66Shc due to its ability to interact with and inhibit $\mathrm{Ca}^{2+}$ signaling by endosomal CXCR4/CCR7.

The finding that p66Shc limits CXCR4/CCR7 recycling, together with its ability to modulate CCR7 and S1PR1 expression [13] and CXCR4 signaling [11], underscores the importance of the p66Shc defect in CLL cell homing to and accumulation in the protective stromal niche. This is supported by the rescue of p66Shc expression in ibrutinibtreated CLL cells, with the resulting inhibition of CXCR4/CCR7 recycling and decrease in surface expression. These data provide a partial explanation for the molecular mechanisms that underlie the massive efflux of leukemic cells from lymphoid tissues and the consequent transient lymphocytosis in ibrutinib-treated patients [34, 51]. We have reported that p66Shc expression is regulated by the transcription factor STAT4, which is profoundly reduced in CLL cells [52], suggesting that ibrutinib may promote p66Shc expression by increasing the levels of STAT4.

In conclusion, we have identified p66Shc as a negative regulator of CXCR4/CCR7 recycling acting at the early-torecycling endosome transit step by preventing their $\mathrm{Ca}^{2}$ ${ }^{+}$-dependent dephosphorylation by receptor-associated PP2B. We have moreover implicated the p66Shc defect in CLL cells in the recycling abnormalities of CXCR4 and CCR7, which contribute to their robust responses to the respective pro-survival stromal ligands. Finally, we provide new insights into the mechanisms underlying the therapeutic effects of ibrutinib in CLL.

\section{Materials and methods}

\section{Patients and healthy donors}

Peripheral blood (PB) samples were collected from 78 patients satisfying standard morphologic and immunophenotypic criteria for CLL. Mutational IGHV status was assessed as reported [53], with a sequence homology $\leq 98 \%$ with the germ-line counterpart considered mutated. B cells from 42 buffy coats were used as adult healthy population controls. At collection, patients had never received treatment. For five patients, PB samples were collected before and after a 4-month Ibrutinib treatment with fixed $420 \mathrm{mg}$ daily dose, administered orally on continuous schedule.

B cells were purified by negative selection using RosetteSep B-cell enrichment Cocktail (StemCell Technologies, Vancouver, Canada) followed by density gradient centrifugation on Lympholite (Cedarlane Laboratories, The Netherlands). 


\section{Cell lines, plasmids, transfections and reagents}

Stable control and p66Shc-expressing transfectants generated using the CLL-derived B-cell line MEC [54] were previously described $[13,20]$. CLL cells were transiently co-transfected with $1 \mu \mathrm{g}$ GFP reporter per sample and $5 \mu \mathrm{g}$ pcDNA3 or p66Shc-encoding pcDNA3 using the Human B-cell Nucleofector Kit (Amaxa Biosystems, Cologne, Germany). Transfection efficiency was $\geq 40 \%$, as assessed by flow cytometry of $\mathrm{GFP}^{+}$cells, and cell viability $48 \mathrm{~h}$ post-transfection was 40-60\%. Human PP2BCA-specific endoribonuclease-prepared small interfering RNAs (esiRNAs) (Mission PPP3CA esiRNA, \#EHU017161) and unrelated control Renilla luciferase (RLUC) esiRNA (Mission RLUC esiRNA, \#EHURLUC) (Sigma-Aldrich, Milan, Italy) were transfected by electroporation and assays carried out after $48 \mathrm{~h}$. For recycling experiments, cells were transiently co-transfected with esiRNAs and pmaxGFP control (Amaxa Biosystems). p66Shc was immunoprecipitated using a rabbit polyclonal antiserum raised against a glutathione S-transferase fusion protein that includes the $\mathrm{N}$ terminal $\mathrm{CH} 2$ domain of p66Shc, allowing for discrimination from the shorter ShcA isoforms. Commercial antibodies used in this study are listed in Supplementary Table 1. Human and mouse CXCL12 and CCL21, S1P, CsA, FK506, okadaic acid, bisindolylmaleimide-1-hydrochloride and fibronectin were purchased from Sigma-Aldrich; ibrutinib from Selleckchem (Munich, Germany); 4-amino-5(bromomethyl)-2-methylpyrimidine hydrobromide from Santa Cruz (Santa Cruz, CA); H89 from MerckMillipore (Darmstadt, Germany). rhICAM-1/Fc was purchased from R\&D Systems. The chemiluminescence detection kit was from Pierce (Rockford, IL).

\section{Mice}

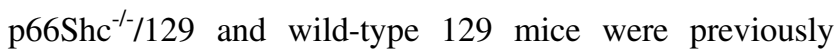
described [55]. Non-randomized non-blinded experiments were carried out on splenic B cells negatively purified by immunomagnetic sorting from age- and sex-matched 2- to 9-month-old mice using the Dynabeads Mouse CD43 Negative Isolation Kit (Invitrogen) (>85\% purity).

\section{Activations, immunoprecipitations, and immunoblots}

Cells were starved for $2 \mathrm{~h}$ in Roswell Park Memorial Institute (RPMI)-1\% bovine serum albumin (BSA) and activated at $37{ }^{\circ} \mathrm{C}$ with $500 \mathrm{ng} / \mathrm{ml} \mathrm{CXCL12} \mathrm{or} 1 \mu \mathrm{g} / \mathrm{ml}$ CCL21 (Sigma-Aldrich). For immunoblots, cells were lysed in $1 \%$ Triton $\mathrm{X}-100,20 \mathrm{mM}$ Tris- $\mathrm{HCl}(\mathrm{pH} 8), 150 \mathrm{mM}$
$\mathrm{NaCl}$ and protease inhibitors (Invitrogen). Postnuclear supernatants were processed for immunoblot as described [56] or immunoprecipitated $\left(2.5-5 \times 10^{7}\right.$ cells per sample $)$ using protein A-Sepharose (GE Healthcare, Little Chalfont, UK) in the presence of the indicated antibody or unrelated immunoglobulin (negative control).

\section{RNA purification and reverse transcriptase-PCR (RT- PCR)}

RNA was extracted and retrotranscribed as described [19]. Real-time PCR was performed in triplicate on 96-well optical PCR plates (Sarstedt AG, Nümbrecht, Germany) using SSo Fast ${ }^{\mathrm{TM}}$ EvaGreen ${ }^{\mathrm{R}}$ SuperMix and a CFX96 RealTime system (Bio-Rad Laboratories, Waltham, MA). Results were processed and analyzed as described [11]. Transcript levels were normalized to HPRT1. Primers used for amplification are listed in Supplementary Table 2.

\section{Analysis of receptor recycling, cell adhesion, chemotaxis, and calcium flux}

Flow cytometry was carried out using a Guava Easy Cyte (Millipore) cytometer. Analysis of surface CXCR4/CCR7 was carried out using fluorochrome-conjugated antibodies or isotype controls. To quantitate the ratio of surface-to-total CXCR4/CCR7, cells were fixed and permeabilized using the Cytofix/Cytoperm plus kit (BD), which does not cause any significant difference in surface CXCR4/CCR7 staining (Supplementary Figure 12). CXCR4/CCR7 recycling following antibody-dependent downregulation was quantitated by flow cytometry as described [57]. Briefly, cells were incubated for $30 \mathrm{~min}$ on ice with receptor-specific Abs, washed, shifted to $37{ }^{\circ} \mathrm{C}$ for $40 \mathrm{~min}$, then subjected to acid stripping (time 0), and incubated for the indicated times at $37^{\circ} \mathrm{C}$. Receptor:Ab complexes that had recycled to the cell surface were measured by labeling with fluorochromeconjugated secondary antibodies. Before S1PR1 staining, cells were resuspended in serum-free medium, $0.5 \%$ fatty acid-free BSA (Sigma-Aldrich) and incubated for $30 \mathrm{~min}$ at $37^{\circ} \mathrm{C}$ to allow recycling of intracellular receptors. Adhesion assays on rhICAM-1/Fc-coated (R\&D Systems) or fibronectin-coated (Sigma-Aldrich) plates in the presence or absence of $100 \mathrm{ng} / \mathrm{ml} \mathrm{CXCL12/CCL21} \mathrm{were} \mathrm{performed} \mathrm{as}$ described [20]. Chemotaxis assays were carried out using 24-well Transwell chambers with $5-\mu \mathrm{m}$ pore polycarbonate membranes (Corning Life Sciences, Schiphol-Rijk, The Netherlands) as described [56]. Analysis of $\mathrm{Ca}^{2+}$ in Fura-2 loaded cells was carried out in $140 \mathrm{mM} \mathrm{NaCl}, 5.4 \mathrm{mM} \mathrm{KCl}$, $1 \mathrm{mM} \mathrm{MgCl}{ }_{2}, 0.2 \mathrm{mM}$ EGTA, $15 \mathrm{mM}$ Hepes, $\mathrm{pH} 7.4$ in the absence of added $\mathrm{Ca}^{2+}$ as described [58]. 


\section{Immunofluorescence microscopy, colocalization analyses, and NFAT assays}

To analyze receptor recycling cells were equilibrated $30 \mathrm{~min}$ at $37^{\circ} \mathrm{C}$ in RPMI- $1 \%$ BSA, incubated with $100 \mathrm{ng} / \mathrm{ml}$ CXCL12/CCL21 at $37^{\circ} \mathrm{C}$ for 10 or $40 \mathrm{~min}$, permeabilized and processed for immunofluorescence microscopy as described [59]. Images were acquired on a Zeiss LSM700 using a $63 \mathrm{X}$ objective as described [59]. The quantitative colocalization analysis of CXCR4/CCR7 with $\beta$-arrestin/ Rab was performed on median optical sections using ImageJ and JACoP plug-in to determine Manders' coefficient [60]. For NFAT assays, cells were transiently transfected with the plasmid pEGFP/NFAT-1D [61] using the Human B-cell Nucleofector Kit (primary B cells) or a modification of the DEAE/dextran procedure (MEC cells), as described [62]. After $24 \mathrm{~h}$, cells were resuspended in RPMI-1\% BSA, stimulated with $100 \mathrm{ng} / \mathrm{ml} \mathrm{CXCL12/CCL21} \mathrm{at} 37^{\circ} \mathrm{C}$ for $1 \mathrm{~h}$

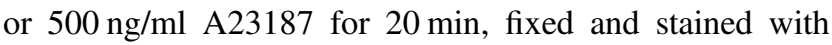
anti-GFP antibodies.

\section{Statistical analyses}

Mean values, standard deviations and Student's $t$-test (unpaired) were calculated using Microsoft Excel. The Mann-Whitney rank sum test was used to analyze CLL samples. A level of $p<0.05$ was considered statistically significant. Sample size, determined on the basis of previous experience in the laboratory, and replicate number for each experimental group/condition are indicated in the figure legends.

\section{Study approval}

Written informed consent was received from CLL patients and healthy donors prior to inclusion in the study according to the Declaration of Helsinki. Experiments were approved by the local Ethics Committee. Animal experiments were carried out according to the Guiding Principles for Research Involving Animals and Human Beings and approved by the local ethics committee.

Acknowledgements The authors wish to thank Sonia Grassini for technical assistance.

Funding This work was carried out with the support of grant AIRC IG-15220 and ITT-Regione Toscana to CTB, AIRC IG-15286, Cariparo and Cariverona to GS and AIRC IG-15397 to LT.

\section{Compliance with ethical standards}

Conflict of interest The authors declare that they have no competing interests.

\section{References}

1. Scarfo L, Ferreri AJ, Ghia P. Chronic lymphocytic leukaemia. Crit Rev Oncol Hematol. 2016;104:169-82.

2. Burger JA, Gribben JG, The microenvironment in chronic lymphocytic leukemia (CLL) and other B cell malignancies: insight into disease biology and new targeted therapies. Semin Cancer Biol. 2014;24:71-81.

3. Munk Pedersen I, Reed J. Microenvironmental interactions and survival of CLL B-cells. Leuk Lymphoma. 2004;45:2365-72.

4. Kehrl JH, Hwang IY, Park C. Chemoattract receptor signaling and its role in lymphocyte motility and trafficking. Curr Top Microbiol Immunol. 2009;334:107-27.

5. Kucia M, Jankowski K, Reca R, Wysoczynski M, Bandura L, Allendorf DJ, et al. CXCR4-SDF-1 signalling, locomotion, chemotaxis and adhesion. J Mol Histol. 2004;35:233-45.

6. Comerford I, Harata-Lee Y, Bunting MD, Gregor C, Kara EE, McColl SR. A myriad of functions and complex regulation of the CCR7/CCL19/CCL21 chemokine axis in the adaptive immune system. Cytokine Growth Factor Rev. 2013;24:269-83.

7. Kurtova AV, Balakrishnan K, Chen R, Ding W, Schnabl S, Quiroga MP, et al. Diverse marrow stromal cells protect CLL cells from spontaneous and drug-induced apoptosis: development of a reliable and reproducible system to assess stromal cell adhesionmediated drug resistance. Blood. 2009;114:4441-50.

8. Ten Hacken E, Burger JA. Microenvironment interactions and Bcell receptor signaling in chronic lymphocytic leukemia: implications for disease pathogenesis and treatment. Biochim Biophys Acta. 2016;1863:401-13.

9. Jin L, Liu WR, Tian MX, Fan J, Shi YH. The SphKs/S1P/S1PR1 axis in immunity and cancer: more ore to be mined. World J Surg Oncol. 2016;14:131.

10. Redondo-Munoz J, Jose Terol M, Garcia-Marco JA, Garcia-Pardo A. Matrix metalloproteinase- 9 is up-regulated by CCL21/CCR7 interaction via extracellular signal-regulated kinase-1/2 signaling and is involved in CCL21-driven B-cell chronic lymphocytic leukemia cell invasion and migration. Blood. 2008;111:383-6.

11. Patrussi L, Capitani N, Martini V, Pizzi M, Trimarco V, Frezzato $\mathrm{F}$, et al. Enhanced chemokine receptor recycling and impaired S1P1 expression promote leukemic cell infiltration of lymph nodes in chronic lymphocytic leukemia. Cancer Res. 2015;75:4153-63.

12. López-Giral S, Quintana NE, Cabrerizo M, Alfonso-Pérez M, Sala-Valdés M, De Soria VG, et al. Chemokine receptors that mediate $\mathrm{B}$ cell homing to secondary lymphoid tissues are highly expressed in B cell chronic lymphocytic leukemia and nonHodgkin lymphomas with widespread nodular dissemination. J Leukoc Biol. 2004;76:462-71.

13. Capitani N, Patrussi L, Trentin L, Lucherini OM, Cannizzaro E, Migliaccio E, et al. S1P1 expression is controlled by the prooxidant activity of p66Shc and is impaired in B-CLL patients with unfavorable prognosis. Blood. 2012;120:4391-9.

14. Kang DS, Tian X, Benovic JL. Role of beta-arrestins and arrestin domain-containing proteins in $\mathrm{G}$ protein-coupled receptor trafficking. Curr Opin Cell Biol. 2014;27:63-71.

15. Gurevich VV, Gurevich EV. Arrestins: critical players in trafficking of many GPCRs. Prog Mol Biol Transl Sci. 2015;132:1-14.

16. Marchese A. Endocytic trafficking of chemokine receptors. Curr Opin Cell Biol. 2014;27:72-77.

17. Otero C, Groettrup M, Legler DF. Opposite fate of endocytosed CCR7 and its ligands: recycling versus degradation. J Immunol. 2006; 177:2314-23. 
18. Zhang Y, Foudi A, Geay JF, Berthebaud M, Buet D, Jarrier P, et al. Intracellular localization and constitutive endocytosis of CXCR4 in human CD34+hematopoietic progenitor cells. Stem Cells. 2004;22:1015-29.

19. Capitani N, Lucherini OM, Sozzi E, Ferro M, Giommoni N, Finetti F, et al. Impaired expression of p66Shc, a novel regulator of B-cell survival, in chronic lymphocytic leukemia. Blood. 2010;115:3726-36.

20. Patrussi L, Capitani N, Cannizzaro E, Finetti F, Lucherini OM, Pelicci PG, et al. Negative regulation of chemokine receptor signaling and B-cell chemotaxis by p66Shc. Cell Death Dis. 2014;5: e1068.

21. Vasudevan NT, Mohan ML, Goswami SK, Naga Prasad SV. Regulation of beta-adrenergic receptor function: an emphasis on receptor resensitization. Cell Cycle. 2011;10:3684-91.

22. Bolinger MT, Ramshekar A, Waldschmidt HV, Larsen SD, Bewley MC, Flanagan JM, et al. Occludin S471 phosphorylation contributes to epithelial monolayer maturation. Mol Cell Biol. 2016;36:2051-66.

23. Zhou T, Song L, Yang P, Wang Z, Lui D, Jope RS. Bisindolylmaleimide VIII facilitates Fas-mediated apoptosis and inhibits T cell-mediated autoimmune diseases. Nat Med. 1999;5:42-48.

24. Murray AJ. Pharmacological PKA inhibition: all may not be what it seems. Sci Signal. 2008;1:re4.

25. Swingle M, Ni L, Honkanen RE. Small-molecule inhibitors of ser/ thr protein phosphatases: specificity, use and common forms of abuse. Methods Mol Biol. 2007;365:23-38.

26. Martinez-Martinez S, Redondo JM. Inhibitors of the calcineurin/ NFAT pathway. Curr Med Chem. 2004;11:997-1007.

27. Schulz RA, Yutzey KE. Calcineurin signaling and NFAT activation in cardiovascular and skeletal muscle development. Dev Biol. 2004;266:1-16.

28. Serfling E, Berberich-Siebelt F, Chuvpilo S, Jankevics E, KleinHessling S, Twardzik T, et al. The role of NF-AT transcription factors in $\mathrm{T}$ cell activation and differentiation. Biochim Biophys Acta. 2000;1498:1-18.

29. Burger JA, Tedeschi A, Barr PM, Robak T, Owen C, Ghia P, et al. Ibrutinib as initial therapy for patients with chronic lymphocytic leukemia. N Engl J Med. 2015;373:2425-37.

30. Lee CS, Rattu MA, Kim SS. A review of a novel, Bruton's tyrosine kinase inhibitor, ibrutinib. J Oncol Pharm Pract. 2016;22:92-104.

31. Byrd JC, Furman RR, Coutre SE, Flinn IW, Burger JA, Blum KA, et al. Targeting BTK with ibrutinib in relapsed chronic lymphocytic leukemia. N Engl J Med. 2013;369:32-42.

32. Cheng S, Ma J, Guo A, Lu P, Leonard JP, Coleman M, et al. BTK inhibition targets in vivo CLL proliferation through its effects on B-cell receptor signaling activity. Leukemia. 2014;28:649-57.

33. Wodarz D, Garg N, Komarova NL, Benjamini O, Keating MJ, Wierda WG, et al. Kinetics of CLL cells in tissues and blood during therapy with the BTK inhibitor ibrutinib. Blood. 2014;123:4132-5.

34. de Rooij MF, Kuil A, Geest CR, Eldering E, Chang BY, Buggy JJ, et al. The clinically active BTK inhibitor PCI-32765 targets Bcell receptor- and chemokine-controlled adhesion and migration in chronic lymphocytic leukemia. Blood. 2012;119:2590-4.

35. Hjortø GM, Larsen O, Steen A, Daugvilaite V, Berg C, Fares S, et al. Differential CCR7 targeting in dendritic cells by three naturally occurring CC-chemokines. Front Immunol. 2016;7:568.

36. Otero C, Eisele PS, Schaeuble K, Groettrup M, Legler DF. Distinct motifs in the chemokine receptor CCR7 regulate signal transduction, receptor trafficking and chemotaxis. J Cell Sci. 2008;121:2759-67.

37. Hauser MA, Legler DF. Common and biased signaling pathways of the chemokine receptor CCR7 elicited by its ligands CCL19 and CCL21 in leukocytes. J Leukoc Biol. 2016;99:869-82.
38. Charest-Morin X, Pepin R, Gagne-Henley A, Morissette G, Lodge $\mathrm{R}$, Marceau F, C-C chemokine receptor-7 mediated endocytosis of antibody cargoes into intact cells. Front Pharmacol. 2013;4:122.

39. Lagane B, Chow KY, Balabanian K, Levoye A, Harriague J, Planchenault $\mathrm{T}$, et al. CXCR4 dimerization and beta-arrestinmediated signaling account for the enhanced chemotaxis to CXCL12 in WHIM syndrome. Blood. 2008;112:34-44.

40. Bamidele AO, Kremer KN, Hirsova P, Clift IC, Gores GJ, Billadeau DD, et al. IQGAP1 promotes CXCR4 chemokine receptor function and trafficking via EEA-1+endosomes. J Cell Biol. 2015;210:257-72.

41. Kennedy JE, Marchese A. Regulation of GPCR trafficking by ubiquitin. Prog Mol Biol Transl Sci. 2015;132:15-38.

42. Berlin I, Higginbotham KM, Dise RS, Sierra MI, Nash PD. The deubiquitinating enzyme USP8 promotes trafficking and degradation of the chemokine receptor 4 at the sorting endosome. J Biol Chem. 2010;285:37895-908.

43. Seachrist JL, Ferguson SS. Regulation of G protein-coupled receptor endocytosis and trafficking by Rab GTPases. Life Sci. 2003;74:225-35.

44. Seachrist JL, Laporte SA, Dale LB, Babwah AV, Caron MG, Anborgh PH, et al. Rab5 association with the angiotensin II type 1A receptor promotes Rab5 GTP binding and vesicular fusion. J Biol Chem. 2002;277:679-85.

45. van IJzendoorn SC, Tuvim MJ, Weimbs T, Dickey BF, Mostov KE. Direct interaction between Rab3b and the polymeric immunoglobulin receptor controls ligand-stimulated transcytosis in epithelial cells. Dev Cell. 2002;2:219-28.

46. Li L, Baxter SS, Gu N, Ji M, Zhan X. Missing-in-metastasis protein downregulates CXCR4 by promoting ubiquitylation and interaction with small Rab GTPases. $J$ Cell Sci. 2017; 130:1475-85.

47. Wienands J. The B-cell antigen receptor: formation of signaling complexes and the function of adaptor proteins. Curr Top Microbiol Immunol. 2000;245:53-76.

48. Bürkle A, Niedermeier M, Schmitt-Gräff A, Wierda WG, Keating MJ, Burger JA. Overexpression of the CXCR5 chemokine receptor, and its ligand, CXCL13 in B-cell chronic lymphocytic leukemia. Blood. 2007;110:3316-25.

49. Calebiro D, Nikolaev VO, Persani L, Lohse MJ. Signaling by internalized G-protein-coupled receptors. Trends Pharmacol Sci. 2010;31:221-8.

50. Bowman SL, Shiwarski DJ, Puthenveedu MA. Distinct G proteincoupled receptor recycling pathways allow spatial control of downstream G protein signaling. J Cell Biol. 2016;214:797-806.

51. Herman SE, Mustafa RZ, Jones J, Wong DH, Farooqui M, Wiestner A. Treatment with ibrutinib inhibits BTK- and VLA-4dependent adhesion of chronic lymphocytic leukemia cells in vivo. Clin Cancer Res. 2015;21:4642-51.

52. Cattaneo F, Patrussi L, Capitani N, Frezzato F, D'Elios MM, Trentin L, et al. Expression of the p66Shc protein adaptor is regulated by the activator of transcription STAT4 in normal and chronic lymphocytic leukemia B cells. Oncotarget. 2016;7:57086-98.

53. Visentin A, Facco M, Frezzato F, Castelli M, Trimarco V, Martini $\mathrm{V}$, et al. Integrated CLL scoring system, a new and simple index to predict time to treatment and overall survival in patients with chronic lymphocytic leukemia. Clin Lymphoma Myeloma Leuk. 2015;15:612-20.

54. Stacchini A, Aragno M, Vallario A, Alfarano A, Circosta P, Gottardi D, et al. MEC1 and MEC2: two new cell lines derived from B-chronic lymphocytic leukaemia in prolymphocytoid transformation. Leuk Res. 1999;23:127-36.

55. Migliaccio E, Giorgio M, Mele S, Pelicci G, Reboldi P, Pandolfi $\mathrm{PP}$, et al. The p66shc adaptor protein controls oxidative stress response and life span in mammals. Nature. 1999;402:309-13. 
56. Patrussi L, Ulivieri C, Lucherini OM, Paccani SR, Gamberucci A, Lanfrancone L, et al. p52Shc is required for CXCR4-dependent signaling and chemotaxis in T cells. Blood. 2007;110:1730-8.

57. Patrussi L, Baldari CT. Analysis of TCR/CD3 recycling at the immune synapse. Methods Mol Biol. 2017;1584:143-55.

58. Gamberucci A, Giunti R, Benedetti A. Progesterone inhibits capacitative $\mathrm{Ca} 2+$ entry in Jurkat $\mathrm{T}$ lymphocytes by a membrane delimited mechanism, independently of plasma membrane depolarization. Cell Calcium. 2004;36:175-80.

59. Finetti F, Paccani SR, Riparbelli MG, Giacomello E, Perinetti G, Pazour GJ, et al. Intraflagellar transport is required for polarized recycling of the TCR/CD3 complex to the immune synapse. Nat Cell Biol. 2009;11:1332-9.
60. Manders EM, Stap J, Brakenhoff GJ, van Driel R, Aten JA. Dynamics of three-dimensional replication patterns during the Sphase, analysed by double labelling of DNA and confocal microscopy. J Cell Sci. 1992;103:857-62.

61. Plyte S, Boncristiano M, Fattori E, Galvagni F, Paccani SR, Majolini MB, et al. Identification and characterization of a novel nuclear factor of activated T-cells-1 isoform expressed in mouse brain. J Biol Chem. 2001;276:14350-8.

62. Boncristiano M, Paccani SR, Barone S, Ulivieri C, Patrussi L, Ilver D, et al. The Helicobacter pylori vacuolating toxin inhibits $\mathrm{T}$ cell activation by two independent mechanisms. J Exp Med. 2003;198:1887-97. 